estra sociedad vive en un planeta con grandes bellezas aturales y rodeada de comodidades derivadas del proestán en conflicto.

Cómo lograr conciliar la protección ambiental con el desarrollo económico, es una interrogante que por más de tres décadas se ha buscado responder por medio del ecodesarrollo, el desarrollo sustentable y por las diversas corrientes de la ciencia económica.

Este breviario titulado Introducción a las economías de la naturaleza, se concentra en los tres principales enfoques que relacionan a la economía con el ambiente: la economía de los recursos naturales y la ambiental, ambas inscritas en la corriente del pensamiento neoclásico, y la economía ecológica, que aporta una visión interdisciplinaria.

Este libro explica, de una manera sencilla, a partir del pensamiento y aportaciones de los teóricos más relevantes, el origen de estos tres enfoques, los conceptos teóricos en los que se basan y sus propuestas. Más importante aún, este Breviario incentiva al lector para que se relacione con el amplio universo de los problemas ambientales. Las fronteras entre estas tres corrientes de la economía del medio ambiente, no están estrictamente delimitadas y en ocasiones sus análisis, así como sus métodos y propuestas, coinciden. Este libro pone de manifiesto las particularidades de cada una de ellas y sus diferencias más importantes.

ISBN 978-607-02-1792-0
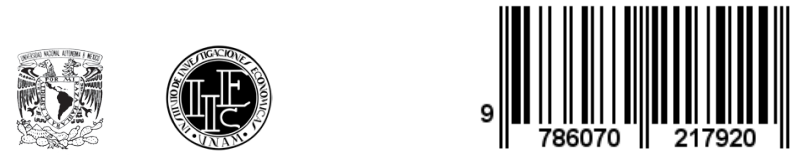

Introducción a las

ECONOMÍAS

DE LA

NATURALEZA

Rosario Pérez Espejo

Sophie Ávila Foucat

Alonso Aguilar Ibarra

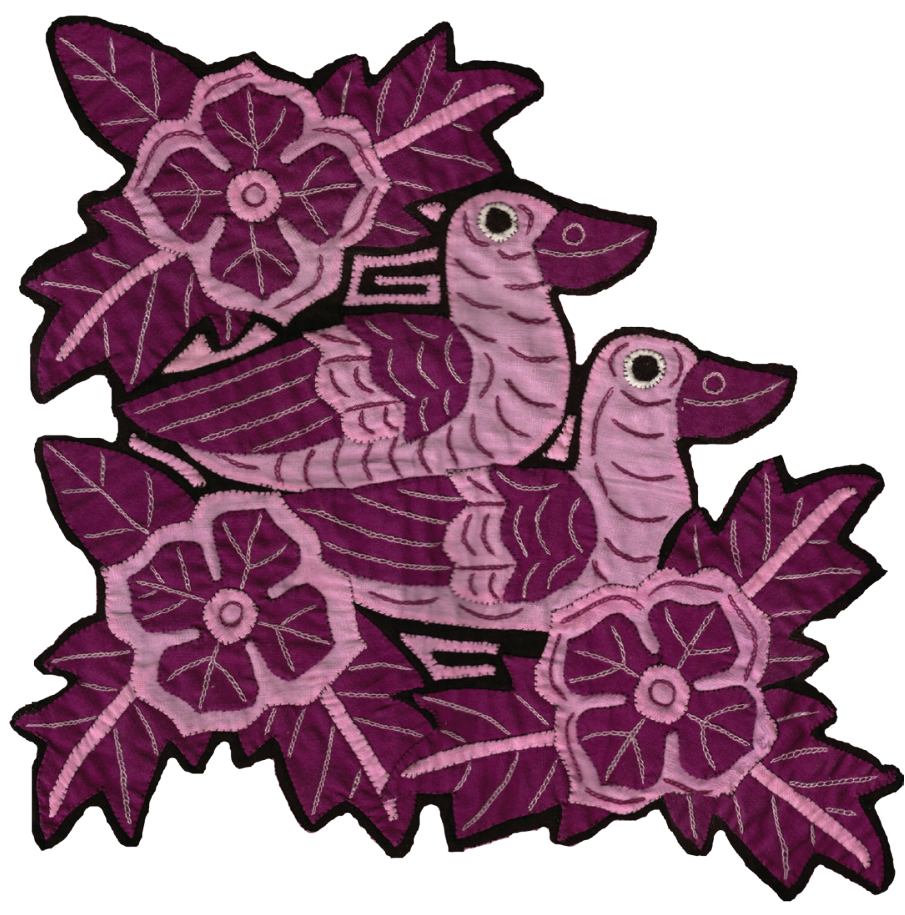


Introducción a las economías de la naturaleza 


\section{致 \\ UNIVERSIDAD NACIONAL AUTÓNOMA DE MÉXICO \\ Dr. José Narro Robles \\ Rector \\ Dr. Sergio Alcocer Martínez de Castro \\ Secretario General \\ Lic. Enrique del Val Blanco \\ Secretario Administrativo \\ Dra. Estela Morales Campos \\ Coordinadora de Humanidades}

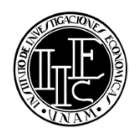

INSTITUTO DE INVESTIGACIONES ECONÓMICAS

Dra. Verónica Villarespe Reyes

Directora

Mtro. Gustavo López Pardo

Secretario Académico

Mtro. Rafael Bouchain Galicia

Secretario Técnico

Lic. Roberto Guerra M.

Jefe del Departamento de Ediciones 


\title{
Introducción \\ a las \\ economías de la naturaleza
}

\author{
Rosario Pérez Espejo \\ Sophie Ávila Foucat \\ Alonso Aguilar Ibarra
}


Esta investigación, arbitrada por pares académicos, se privilegia con el aval de la institución editora.

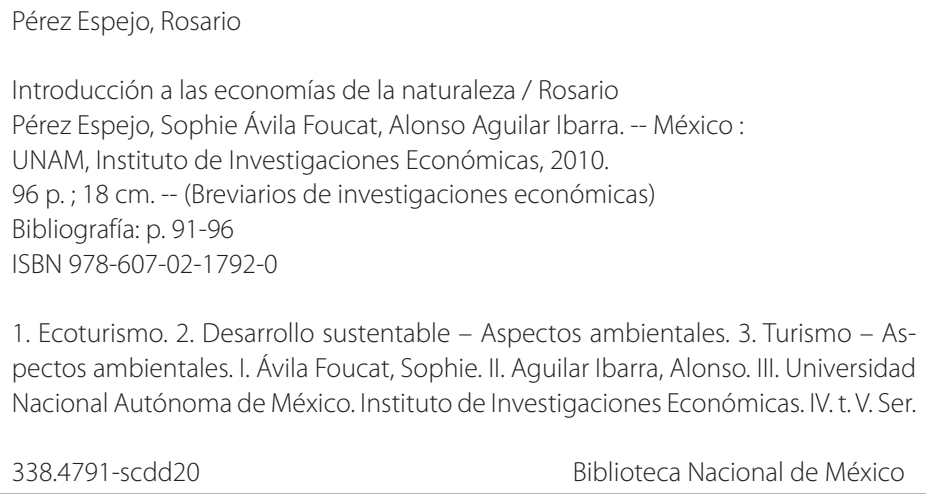

1. Ecoturismo. 2. Desarrollo sustentable - Aspectos ambientales. 3. Turismo - Aspectos ambientales. I. Ávila Foucat, Sophie. II. Aguilar Ibarra, Alonso. III. Universidad Nacional Autónoma de México. Instituto de Investigaciones Económicas. IV. t. V. Ser.

$338.4791-s c d d 20$

Biblioteca Nacional de México

Primera edición

30 de octubre de 2010

D.R. () Universidad Nacional Autónoma de México

Ciudad Universitaria, Coyoacán, 04510, México, D.F.

INSTITUTO DE INVESTIGACIONES ECONÓMICAS

Circuito Mario de la Cueva s/n

Ciudad de la Investigación en Humanidades

04510, México, D.F.

ISBN 978-607-02-1792-0

Diseño de interiores: Marisol Simón y Enrique Amaya.

Diseño de portada: Gabriela Sánchez Martínez.

Imagen: detalle de mola, de la comarca Kuna Yala, Panamá.

Cuidado de la edición: Hélida De Sales Y.

Prohibida la reproducción total o parcial por cualquier medio sin la autorización escrita del titular de los derecho patrimoniales.

Impreso y hecho en México 


\section{ÍNDICE}

$\begin{array}{ll}\text { PRESENTACIÓN } & 9\end{array}$

$\begin{array}{ll}\text { INTRODUCCIÓN } & 11\end{array}$

1. ECONOMÍA DE LOS RECURSOS NATURALES

2. ECONOMÍA AMBIENTAL 39

3. ECONOMÍA ECOLÓGICA 69

$\begin{array}{ll}\text { BIBLIOGRAFÍA } & 91\end{array}$ 


\section{PRESENTACIÓN}

La colección Breviarios de Investigaciones Económicas ofrece a los lectores temas actuales, de interés social y académico, presentados de manera sucinta y atractiva. Así mismo, están elaborados con visión amplia, rigor y acuciosidad en el análisis de los tópicos tratados.

Los autores, especialistas del tema que tratan, decantan el saber vigente; cada Breviario entonces se convierte en una oportunidad para conocer el estado que guarda la temática abordada y cumple con el propósito de despertar el interés del lector, y ponen a su disposición la bibliografía pertinente para profundizar en la problemática tratada.

El otro propósito de los Breviarios de Investigaciones Económicas es hacer que el conocimiento llegue a más personas, una de las actividades fundamentales de la Universidad Nacional Autónoma de México y por ende del Instituto de Investigaciones Económicas, porque difundir es reproducir y acrecentar el saber.

Verónica Villarespe Reyes

Directora

Instituto de Investigaciones Económicas, UNAM 


\section{INTRODUCCIÓN}

Los efectos ambientales así como sus variadas manifestaciones, han sido objeto de creciente atención en las últimas cuatro décadas por parte de grupos de la sociedad -conocidos originalmente como ambientalistas-, por las autoridades y por los sectores de la academia. No obstante, 50 años después hay múltiples evidencias de que las medidas para resolver por lo menos algunos de los más graves problemas que la relación del humano con su ambiente genera son insuficientes.

Las razones que explican la incapacidad de sociedades como la nuestra para crear soluciones viables a los problemas ambientales son diversas: falta de información puntual y suficiente, escasez de recursos humanos capacitados en el tema, problemas metodológicos, costo de las soluciones de mitigación, enfoques teóricos opuestos, visión de corto plazo, incentivos económicos mal dirigidos y falta de educación ambiental, entre otras.

Como institución académica, el Instituto de Investigaciones Económicas está interesado en difundir las actividades de su personal y coadyuvar a la formación de recursos humanos; en este sentido, el presente breviario tiene como propósito proporcionar al lector una rápida visión de los tres enfoques que analizan los efectos de las actividades econó- 
micas en el ambiente: la economía de los recursos naturales y la ambiental, inscritas en la corriente del pensamiento neoclásico, y la economía ecológica, con una visión interdisciplinaria.

El breviario presenta una visión del desarrollo de estas corrientes teóricas en el tiempo; por tanto, inicia con la economía de los recursos naturales, cuyos primeros atisbos datan de fines del siglo xix; continúa con la economía ambiental, cuyos primeros textos, ahora clásicos, aparecen a finales de la década de 1960 y la primera mitad de los setenta, y concluye con la economía ecológica, que durante la década de 1980 se construye como una crítica y una alternativa a las corrientes anteriores.

Las fronteras entre estas tres corrientes de la economía del medio ambiente no están estrictamente delimitadas y en ocasiones tanto sus análisis como sus métodos y propuestas pueden ser coincidentes. Sin embargo, el breviario señala las particularidades de cada una y sus diferencias más importantes.

Este breviario explica de manera sencilla el origen de las tres corrientes analizadas, los conceptos teóricos en que se basan y las propuestas que generan a partir de un recorrido por el pensamiento y las aportaciones de sus teóricos más relevantes. Pero aún más importante, esta obra incentiva al lector no sólo a que se asome al amplio universo de los problemas ambientales, sino a que se involucre con éste. 


\section{ECONOMÍA DE LOS RECURSOS NATURALES}

A lo largo de la historia, las civilizaciones han obtenido beneficios de los recursos naturales para la alimentación, la construcción, como fuentes de energía o incluso como depósitos de desechos. Así, el crecimiento económico se ha apoyado en el uso de los recursos naturales. Sin embargo, el análisis académico de estos aspectos no es tan longevo, pues si bien comenzó con unos primeros trabajos en el siglo xIx, es a partir del estudio seminal de Hotelling en los años treinta cuando se propone la regla de extracción óptima, conocida como la ecuación fundamental de la economía de los recursos naturales agotables o regla de Hotelling. La dificultad matemática de su trabajo para la época resultó en un olvido académico del tema.

No obstante, en 1952 se publica una obra que retoma el interés en la economía de los recursos naturales: Conservación de los recursos: economía y política, de S. V. CiriacyWantrup. A partir de esa década se desarrollan los modelos sobre la pesca -de modo notable con el modelo SchaeferGordon-, se retoman los trabajos de Faustmann respecto a los bosques y, en la década de 1980, Colin Clark define la ecuación fundamental de la economía de los recursos naturales renovables, con lo que generaliza de manera formal el trabajo de Hotelling. 
Actualmente la economía de los recursos naturales emplea los conceptos neoclásicos de optimización en el tiempo, es decir, la teoría del control óptimo, así como la teoría de juegos.

\section{DeFinIR LOS RECURSOS NATURALES: UNA CUESTIÓN DE ESCALA}

Por lo general los recursos naturales se clasifican en renovables y no renovables según su tasa de recuperación. Si ésta es cero, cualquier cantidad que se extraiga del recurso se perderá y de continuar con la extracción se llegará a un agotamiento total, como puede ser el caso de un yacimiento de petróleo o gas. En contraste, los recursos que crecen de manera natural, es decir, los que tienen una tasa de recuperación mayor que cero, pueden renovarse siempre y cuando la tasa de extracción sea menor que la de recuperación; tal es el caso de los bosques o los peces.

Sin embargo, esta definición puede ser ambigua porque depende del ámbito espacial y temporal al que se hace referencia. Un ejemplo es el agua. La cantidad total de agua que hay en el planeta es casi la misma desde hace millones de años, sólo que, por el hecho de ser un flujo, su disponibilidad cambia tanto local como temporalmente. Así, el agua es un flujo constante que pasa de un estado sólido a uno líquido y a uno gaseoso en la naturaleza; pero también es un flujo al cambiar de lugar en forma de ríos superficiales y subterráneos, que por gravedad confluyen en ríos de mayor tamaño, en depósitos superficiales (lagos, lagunas, mares) o subterráneos (acuíferos). Ésta es la llamada agua meteórica, que se encuentra en circulación constante y forma el ciclo 
hidrológico. El agua fósil, en cambio, es la que se encuentra en acuíferos totalmente aislados de esta circulación.

Pero si el agua está en una cantidad constante, hablar de ella como recurso natural renovable o no renovable sólo tiene sentido cuando definimos la escala de análisis. Por ejemplo, el agua meteórica es renovable pero puede agotarse de manera local (en un acuífero) si la tasa de extracción es mayor que la de su renovación o si las fuentes de abastecimiento o recarga son cortadas; no obstante, si la extracción permite la recuperación del líquido, entonces puede aprovecharse en forma sustentable.

En contraste, un acuífero con agua fósil representa un recurso natural no renovable y cada litro extraído no se recuperará en un lapso relevante para la economía, aunque de hecho el agua fósil formó parte del ciclo hidrológico en un pasado muy remoto. En el extremo, aun el petróleo es un recurso natural renovable si tomamos una escala temporal de miles de millones de años.

Hay otros ejemplos que también son difíciles de definir. Pongamos el caso de una selva tropical. Una vez que se tala por completo, la sucesión de especies vegetales puede dar lugar a un ecosistema diferente del que había antes de la intervención humana. Por tanto podríamos pensar que, en algunos casos, es posible que una colección de especies endémicas que forman un determinado ecosistema sea un recurso natural no renovable. Esta característica no se limita a la degradación antropogénica, también se aplica en el caso de catástrofes naturales que pueden cambiar grandes extensiones, como las erupciones volcánicas o el impacto de un meteorito gigante. Pero también estos cambios dependerán de la escala de análisis a la cual hacemos referencia. 
En resumen, la clasificación de renovable y no renovable es artificial y debe definirse para un ámbito espacial y temporal determinado. Otra clasificación con la que puede complementarse es el concepto de reservas y flujos. Una reserva es algo que se encuentra en la naturaleza por periodos largos y que es fácilmente identificable. Los ejemplos son, de nuevo, un acuífero, un bosque o un yacimiento de petróleo. Los flujos son más dinámicos tanto en tiempo como en espacio pero están estrechamente ligados a las reservas: un flujo de entrada en una reserva (o banco) de peces correspondería al crecimiento en número o tamaño de los peces, mientras que un flujo de salida estaría representado por la cantidad extraída mediante la pesca. La energía solar o la eólica pueden considerarse recursos con tasa de renovación infinita porque se aprovechan en forma de flujo pero no de reserva, aunque para poder utilizar la energía se requiere convertirlos por medio de una tecnología (como celdas o pilas), en reserva, que es finita y depende de la aplicación de dicha tecnología para su aprovechamiento. El caso de la energía atómica es parecido: se basa en la extracción mineral pero su empleo depende de una tecnología de transformación (enriquecimiento de uranio). Entonces, estos tipos de energía serán renovables mientras una tecnología de almacenamiento sea costeable o esté disponible. 
La regla de Hartwick: sustentabilidad fuerte y débil

La importancia de los recursos naturales como factores para el desarrollo económico se evidenció durante las últimas décadas, sobre todo a partir de la aceptación del concepto de desarrollo sustentable. Esto puede percibirse, por ejemplo, en la evolución de los títulos de las conferencias de las Naciones Unidas sobre desarrollo económico. En 1972 aún tenía un título antropocéntrico: Conferencia de las Naciones Unidas sobre el Ambiente Humano o Conferencia de Estocolmo. Después de veinte años (en 1992), al reconocer que el desarrollo económico está ligado con el ambiente, la ideología del desarrollo sostenible cristaliza y ello se demuestra en el nombre Conferencia de las Naciones Unidas sobre el Medio Ambiente y Desarrollo, en Río de Janeiro. Una década más tarde, la designación Cumbre de la Tierra (Río+10), en Johannesburgo (2002), promete dos cosas: por un lado, ver a la Tierra como un todo olvidando el antropocentrismo y, por otro, la continuidad de los compromisos de la Agenda 21 firmados en Río de Janeiro. Si bien el grado de adopción de estos acuerdos es muy heterogéneo entre los países firmantes, se considera un avance importante para la política ambiental global.

El desarrollo sustentable puede analizarse desde dos enfoques: como sustentabilidad débil o fuerte, términos que tienen su origen en una desigualdad matemática de la llamada regla de Hartwick [Neumayer, 1999]. Originalmente, John Hartwick, basándose en los trabajos de Robert Solow, definió la sustentabilidad como la inversión neta total 
(INT) de cualquier tipo de capital que se mantuviera igual o mayor que cero a lo largo del tiempo: INT $\geq 0$, lo que en términos matemáticos se denomina desigualdad débil. Así, la regla de Hartwick definió la sustentabilidad como la capacidad de mantener una reserva de capital "no negativa" a lo largo del tiempo, lo que significa que el capital creado y mantenido puede ser o no natural. Es decir, en teoría, si la creación de infraestructura o tecnología permite sustituir el capital natural (por ejemplo, minerales o árboles), manteniendo por lo menos constante la utilidad generada, entonces se cumplirán los principios del desarrollo sustentable.

Por otro lado, David Pearce modificó la regla de Hartwick al proponer que la inversión en el capital natural o su mantenimiento fuera estrictamente positiva, lo que implica: INT >0 y en términos matemáticos se denomina desigualdad fuerte. De aquí surgió el término sustentabilidad fuerte, concepto donde el capital natural se asume como insustituible, por lo que evita la posibilidad de perder capital natural a expensas del creado por el humano. De esta manera, no es posible tener una inversión total mayor que cero dedicada sólo al capital creado, sin capital natural. Aquí se supone que el capital natural y el manufacturado son complementos, no sustitutos.

El fondo de este debate reside en la tasa de sustitución de ambos tipos de capital (natural vs. creado), y un ejemplo simple es el siguiente: un niño que nazca en el futuro, después de la extinción de una especie de ballena, no tendrá el bienestar (o utilidad) obtenido de fotografiar o acariciar a este mamífero marino. Pero, al mismo tiempo, el hecho de que este niño nunca conoció a las ballenas no le generará una pérdida de bienestar o utilidad porque puede disfru- 
tar de un videojuego en tercera dimensión sin percibir un daño por la pérdida de biodiversidad.

En otras palabras, la utilidad de este niño futuro es positiva gracias a la tecnología (capital creado), sin necesidad de santuarios para mamíferos marinos $y$, por lo tanto, desde la perspectiva de la sustentabilidad débil, las generaciones futuras tienen bienestar gracias al desarrollo tecnológico.

Ésta es una diferencia significativa con un niño del presente que ya visitó un santuario, disfrutó enormemente la experiencia como única y tiene el deseo de regresar o llevar a sus hijos a ver y tocar a las ballenas. Si el "niño futuro" tiene la misma oportunidad que este "niño presente", entonces las generaciones futuras considerarán insustituibles a las ballenas. Es decir, desde el enfoque de la sustentabilidad fuerte, las ballenas (y el capital natural en general) deberían ser preservadas en forma permanente.

Otro tema para el debate es que también el desarrollo tecnológico y el económico dependen de la preservación de los recursos naturales. Un ejemplo es la fabricación de componentes electrónicos que requiere agua de extrema pureza, a menudo proveniente de acuíferos no renovables. Sin este tipo de agua no sería factible fabricar los componentes de muchos aparatos de la vida cotidiana. Pero el debate continúa porque hay la posibilidad de inventar un proceso tecnológico que no utilice agua' -la discusión sobre los límites biofísicos para el desarrollo se detallará en el capítulo de economía ecológica en esta misma obra.

1 Para profundizar en este debate por demás interesante se recomienda revisar Ecological Economics, vol. 22, año 1997, pp. 261-279, en el que se desarrolla una discusión entre varios expertos: Herman E. Daly, Robert M. Solow, Joseph E. Stiglitz, Colin W. Clark y Michael Common. 
Pearce y Turner [1990] proponen una definición que intenta conciliar la sustentabilidad fuerte y débil:

[...] mantener los servicios ecológicos y la calidad ambiental del capital natural a lo largo del tiempo, implica aceptar las siguientes reglas:

a) extraer los recursos renovables a una tasa menor o igual a la tasa de regeneración natural de los mismos y

b) optimizar la eficiencia con la cual se utilizan los recursos no renovables, sujeta a la factibilidad de sustitución entre capital natural y progreso tecnológico.

Herman Daly [2005] menciona, además, que no debe sobrepasarse la capacidad de carga de los ecosistemas (véase el capítulo 3).

El espejismo de la curva ambiental de Kuznets

En países pobres o en economías emergentes es muy común que los problemas de degradación ambiental sean considerados "el precio a pagar" para lograr el crecimiento económico. Por tanto, las políticas públicas que fomentan la extracción desmedida de recursos naturales (como los subsidios al diesel para aumentar el esfuerzo pesquero) o la contaminación (los subsidios para la compra de agroquímicos) tienen un lugar prioritario en el mantenimiento de la calidad del ambiente.

La idea errónea de que la degradación ambiental disminuye conforme los países tienen un mayor ingreso per cápita se basa en la curva ambiental de Kuznets. Ésta, que se representa en forma de $\mathrm{U}$ invertida al graficar ingreso y nivel de degradación ambiental, ha servido como justificación 
para decir que los países más ricos resuelven sus problemas ambientales una vez que se desarrollan económicamente; de aquí la negligencia en países menos desarrollados.

Sin embargo, según Arrow et al. [1995], la curva ambiental de Kuznets:

- Parece válida para algunos contaminantes que implican costos de corto plazo (sulfuro, partículas y coliformes), pero no para la acumulación de contaminantes que conllevan costos dispersos y de largo plazo (dióxido de carbono).

- Se ha demostrado para contaminantes, no para el agotamiento de los recursos naturales.

- No dice cosa alguna sobre las consecuencias internacionales de la reducción de contaminantes.

- En muchos casos el abatimiento de la contaminación se ha logrado gracias a reformas institucionales locales y no por un aumento en el ingreso.

Por lo tanto, el crecimiento económico no es la panacea para la calidad ambiental, y lo que importa para alcanzar el desarrollo sostenible es cómo se da ese crecimiento: la composición de insumos (incluso recursos naturales) y productos (aun desechos), y la función determinante de las instituciones en las que se realizan las actividades humanas.

Proteger la capacidad de los ecosistemas para sostener el bienestar humano tiene la misma importancia en países ricos y pobres [Arrow et al., 1995], aunque para la mayor parte de los más pobres el camino hacia el desarrollo sustentable requiere una gestión cuidadosa del ambiente, de tal manera que el capital natural no se deprecie tanto que el progreso económico futuro nunca llegue [Turner, 2001]. 
Ésta es una discusión en la que deben intervenir diversos sectores de la sociedad, entre ellos profesionistas pertenecientes a distintas disciplinas. De aquí que el esfuerzo que conlleva un crecimiento sustentable con equidad es todavía una tarea pendiente para nuestra sociedad.

\section{EXTRACCIÓN DE RECURSOS NATURALES}

La elección intertemporal

Los ejemplos de la sección anterior dejan en claro que la cuestión primordial implícita en el concepto del desarrollo sustentable es de tipo intertemporal: una decisión entre hoy y mañana que resulta fundamental para la gestión de los recursos naturales, porque lo que se hace hoy tendrá consecuencias mañana.

Pero la sociedad tiene una preferencia por el tiempo, es decir, hay una inclinación natural a valorar de manera distinta la posesión de un bien en el presente y en el futuro. El ejemplo clásico es preguntar: ¿Qué prefieres, 100 pesos hoy o dentro de un año? Aceptarlos hoy significa gastarlos o invertirlos en el banco y si la tasa de interés es de 10\%, entonces dentro de un año tendrás 110 pesos. Pero aceptarlos dentro de un año significa que no se disfrute de las compras de hoy o no se gane ese 10\% adicional. En este caso el costo de oportunidad es el sacrificio de no consumir o el beneficio monetario de 10 pesos. Por consiguiente, y casi de modo invariable, la respuesta es: "Ios prefiero hoy", porque en general la sociedad es impaciente y prefiere los beneficios de hoy sobre los de mañana. Esta valoriza- 
ción diferida se conoce como preferencia temporal y es una cuestión de costo de oportunidad: comparar los beneficios de hoy con los de mañana. Si traducimos esta metáfora al contexto de los recursos naturales:

- La cantidad ofrecida equivale al stock natural.

- Aceptar el dinero equivale a extraer el recurso.

- La tasa de interés equivale a la tasa de descuento. ${ }^{2}$

Aquí entra la decisión con los costos de oportunidad implícitos; por ejemplo: en un futuro a cinco años, un pescador compara sus ganancias si captura todos los peces e invierte el dinero en el banco o deja crecer el stock para obtener los beneficios en el futuro. Entre más alta sea la tasa de descuento, menos importancia se da al futuro y los recursos naturales se agotan con más rapidez. Por otra parte, una tasa de descuento baja implica más sacrificios para las generaciones presentes pero en beneficio de las futuras.

El punto clave es, entonces, cuánto y cuándo extraer un recurso natural. Es decir, ¿cuál es la extracción óptima o sostenible?

Recursos renovables: la extracción sostenible

Los recursos naturales renovables poseen la capacidad natural de crecer a lo largo del tiempo. Así, el tamaño de una población o reserva del recurso en un periodo determinado está en función de su crecimiento y de la extracción durante

2 La tasa de descuento equivale a la tasa de interés si asumimos que no hay riesgo ni otros factores, como el tipo de cambio. De hecho, la tasa de interés es una forma de medir el riesgo en una economía. 
el periodo si está sometido a la utilización humana. Esto puede representarse en una ecuación de la siguiente manera:

$$
S_{t}=S_{t-1}+G_{t}-E_{t}
$$

$$
\begin{gathered}
\text { Tamaño del } \\
\text { recurso al final } \\
\text { del periodo } t
\end{gathered}=\begin{gathered}
\text { Tamaño inicial } \\
\text { del recurso en } \\
\text { el periodo } \\
\text { anterior }
\end{gathered}+\begin{gathered}
\text { Crecimiento } \\
\text { del recurso } \\
\text { durante el } \\
\text { periodo } t
\end{gathered}-\begin{gathered}
\text { Extracción } \\
\text { del recurso } \\
\text { durante el } \\
\text { periodo } t
\end{gathered}
$$

Sin embargo, el crecimiento tiene un límite impuesto tanto por el ambiente donde está inmersa la población como por la naturaleza biológica de cada recurso; este límite se denomina capacidad de carga de la población (K). En términos teóricos, cuando la población tiene un tamaño igual que K, se dice que está en su máxima capacidad y por lo tanto en equilibrio, y si hay muertes o emigraciones durante el periodo, los nacimientos o inmigraciones mantienen el equilibrio de la población total.

En este contexto, las extracciones se suman a las pérdidas naturales, pero regresar al nivel de equilibrio K dependerá de la magnitud tanto de la tasa de extracción como de la de recuperación. Si esta última es menor a la tasa de extracción, la población no alcanzará K en el periodo en cuestión y la población disminuirá paulatinamente hasta que se agote si en los siguientes periodos se extrae cada vez la misma cantidad. En otras palabras, el recurso natural no podrá sostenerse; pero no sólo el recurso, también las extracciones disminuirán a la par y tampoco podrán sostenerse, lo que traerá consecuencias económicas y sociales para la industria o región que depende del recurso natural.

En cambio, tanto las poblaciones ecológicas como las extracciones (que son una actividad económica) podrán man- 
tenerse a lo largo del tiempo si la tasa de extracción es menor que a la de recuperación natural. Esto se ilustra en la gráfica 1.

Si las extracciones no exceden un límite en el cual se permita que la población se recupere en un periodo dado, entonces serán sustentables; este límite se conoce como el máximo rendimiento (de extracciones) sostenible. Rebasar este umbral a menudo llevará al agotamiento de la población. ¿Cuál es el tamaño de la población que corresponde a este rendimiento? La respuesta depende de cada recurso. Por ejemplo, la tasa de recuperación de una población de camarón puede

\section{Gráfica 1}

Ejemplo teórico de extracciones sostenibles de un recurso natural renovable, suponiendo constantes otros factores, como la variabilidad climática

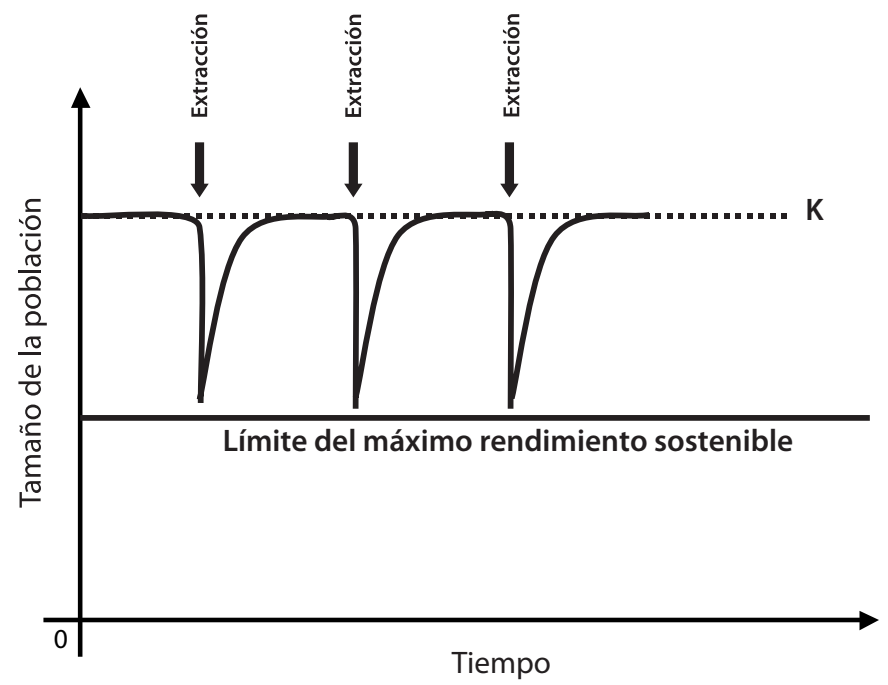

Fuente: Elaboración propia. 
ser de varios meses; la de algunos peces, de un año; la de árboles, de décadas, y la de un acuífero grande, de siglos.

Es importante notar que la gráfica 1 muestra un mundo sin incertidumbre. La realidad es mucho más compleja porque las tasas de recuperación e incluso de capacidad de carga de los recursos naturales varían de acuerdo con las condiciones climáticas y las interacciones ecológicas. Además, la industria de extracción, en contraparte, está a merced de fluctuaciones en los precios y de cambios políticos y sociales, entre otros. Por ello, estimar con exactitud el rendimiento máximo sostenible de las extracciones es muy difícil en la práctica; sin embargo, los principios teóricos del modelo son útiles para comprender esta interacción entre la economía y la naturaleza.

Recursos no renovables: I regla de Hotelling

Con base en el mismo modelo, la diferencia fundamental con los recursos no renovables es que la tasa de crecimiento de éstos es igual que cero:

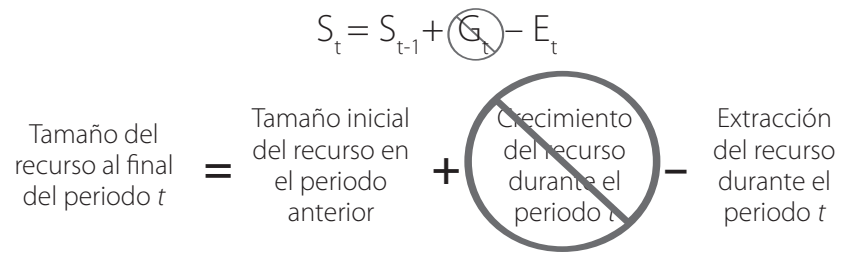

La tasa de extracción siempre es mayor que la de renovación y, por lo tanto, a una tasa constante de extracción, el recurso se perderá tarde o temprano. Aquí valdría plantear la siguiente pregunta: ¿hay un más tarde o un más temprano que sea óptimo o sostenible? En otras palabras, si de cualquier manera se agotará el recurso, ¿hay un criterio 
para establecer una tasa óptima de extracción? La respuesta es sí y se conoce como la regla de Hotelling: la tasa óptima de extracción de un recurso natural no renovable es aquella en la cual la tasa de aumento del precio del recurso es igual que la tasa de descuento de la sociedad.

Para explicar de otra manera este concepto hay que referirse a la curva inversa de la demanda, en la que la cantidad demandada determina el precio de un bien. Esta cantidad se refiere a la extracción del recurso que va disminuyendo la disponibilidad total y, al mismo tiempo, al volverse cada vez más escaso, su precio aumenta. ${ }^{3}$ Esto sucede a través del tiempo porque la extracción de un recurso natural no renovable que se considera valioso, por lo general no se detiene sino hasta su agotamiento. Mientras dura este proceso, el valor del dinero que representa el yacimiento disminuye $y$, en consecuencia, las expectativas sobre el futuro cambian. Como ya se mencionó, la sociedad lo expresa por medio de la tasa de descuento y la regla de Hotelling dice que la tasa de cambio del precio de este recurso a lo largo del tiempo debe igualar la preferencia temporal de la sociedad.

De hecho, los yacimientos de hidrocarburos y minerales se agotan porque en el corto plazo representan costos menores para la sociedad que las energías alternativas. En la economía de los recursos naturales, éstas se consideran sustitutos (tecnologías backstop, como la eólica o la solar) una vez que se agotaron las reservas no renovables. En otras

3 Cæteris paribus, que es el término que los economistas usan para indicar que asumimos que otros factores no cambian y que ayuda para simplificar un análisis. 
palabras, la sociedad no invertirá en tecnologías alternativas sino a partir del agotamiento de las reservas tradicionales.

El resultado descrito en el párrafo anterior depende por supuesto de los costos de extracción y, en la práctica, son éstos los que a veces pueden salvaguardar los recursos naturales. En el caso de un yacimiento, específicamente de gas o petróleo, la consideración de los costos de extracción es muy importante para su administración, y la manera más frecuente de representarlos es por medio de la caja tipo McKelvey (esquema 1).

La caja McKelvey muestra que los yacimientos naturales pueden encontrarse en grandes cantidades en el subsuelo;

\section{Esquema 1}

Caja tipo McKelvey para las reservas no renovables

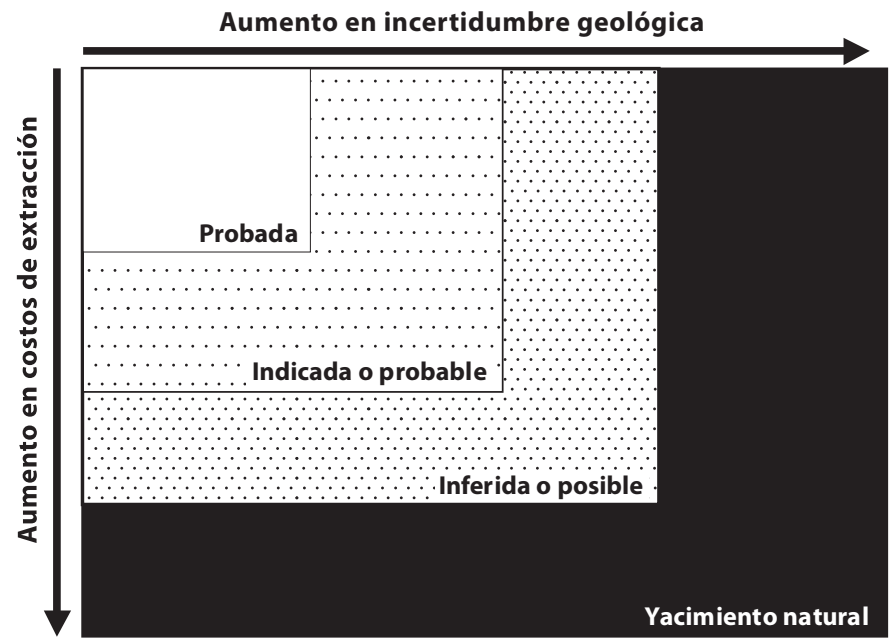

Fuente: Modificado de Tietenberg [1994]. 
sin embargo, el conocimiento exacto de dónde se localizan (incertidumbre geológica) y el costo necesario para acceder a ellos (costos de extracción) hacen que su disponibilidad total sea técnicamente imposible. De ahí que estas reservas se clasifiquen en tres tipos (llamadas las 3 P): reservas probadas (se sabe con exactitud dónde se encuentran y cuál es su magnitud), reservas probables o indicadas (se tienen indicadores de dónde se encuentran pero no se conoce su tamaño exacto) y reservas posibles o inferidas (no se sabe exactamente dónde ni cuánto hay, pero se piensa que deben de "estar por ahi"). Como se puede apreciar, tanto el costo de extraer como la incertidumbre de su magnitud y localización son mayores para las reservas posibles que para las probables y las probadas.

\section{EL PROBLEMA DEL ACCESO ABIERTO}

Externalidad por falta de claridad en el régimen de propiedad

Aunque la problemática de los recursos naturales es muy compleja, la economía suele encuadrarla en dos problemas principales: a) el momento y la cantidad de extracción, y b) el acceso a los recursos. Mientras la sección anterior se refirió al primer punto, ésta se dedica a los problemas del acceso abierto.

El régimen de propiedad es también un tema complicado por las distintas manifestaciones que presenta; por ejemplo, cuando un particular identificable tiene un certificado de propiedad de un bien, éste no puede pertenecer a otra persona a menos que haya un intercambio voluntario. 
Los recursos naturales de México son propiedad de la nación según el artículo 27 constitucional, pero al mismo tiempo son bienes comunes porque hay muchos "dueños" (todos los mexicanos) y por lo mismo todos estos dueños pueden tener acceso a los recursos naturales: pueden ser de libre acceso.

Para evitar su agotamiento, el gobierno salvaguarda, controla y administra los recursos naturales, y en muchos casos necesitará restringir el acceso en aras del bien común. El Estado puede conceder o permitir el uso a un individuo o un grupo, lo que puede considerarse privatización; sin embargo, lo que se privatiza es el uso, no el recurso. De cualquier manera, para Costanza [2000], limitar el análisis del régimen de propiedad de recursos naturales al enfoque públicoprivado es incorrecto y debería hablarse de regímenes de propiedad individual, común o colectiva; por ejemplo, un ejido es al mismo tiempo un régimen de propiedad privado y común. En algunas ocasiones los títulos de propiedad común son de tipo informal otorgados por tradición (usos y costumbres). Pero si no hay reglas claras, ni autovigilancia, puede llegarse a un régimen de acceso abierto de facto y permanece la percepción de que nadie posee el recurso pero cualquier usuario puede aprovecharlo.

En la extracción de recursos naturales bajo acceso abierto es frecuente observar externalidades; puesto que nadie posee o controla la cantidad extraída total, nadie tiene incentivos para cuidar el recurso y todos tratan de extraer lo máximo posible antes de que otros lo hagan. Los pescadores, taladores y cazadores se afectan mutuamente, generan entre ellos externalidades. Hay un costo extra para el individuo por la falta de peces (o de árboles o de venados), pero 
también hay un costo para la sociedad. Nadie se interesa en las consecuencias del agotamiento del recurso ni en las del aumento del costo.

Éste es el origen de la famosa tragedia de los comunes de Garret Hardin [1968], quien utilizó este término en sentido literario: la tragedia es el relato de algo fatídico o inevitable que describe la situación del acceso libre. En sentido opuesto, Elinor Ostrom [1990] considera que este "final" sí puede modificarse y lograrse el aprovechamiento sustentable por medio de la participación de usuarios en la gestión de los recursos naturales.

Participación de usuarios en la gestión

La idea central es que la participación de los usuarios en la toma de decisiones es unamanera defortalecerlas instituciones participantes y disminuir los conflictos en la utilización de los recursos naturales. Sen y Nielsen [1996] definen el comanejo como un espectro de posibilidades de participación que va desde el control total del gobierno hasta la autogestión total (diagrama 1). En el extremo izquierdo del diagrama, el gobierno toma la decisión y da instrucciones para proceder; hacia la derecha, el gobierno puede consultar, pero de todos modos tiene la última palabra. La cooperación entre gobierno y usuarios resulta en una toma de decisiones conjunta; este tipo de comanejo no debe confundirse con la gestión cooperativa de Ostrom, en la cual la cooperación se da fundamentalmente entre usuarios. Así pues, el comanejo implica una gama de posibilidades en la relación gobierno-usuario que a su vez permitiría la cooperación entre usuarios, que es la tesis central de Ostrom. Por 


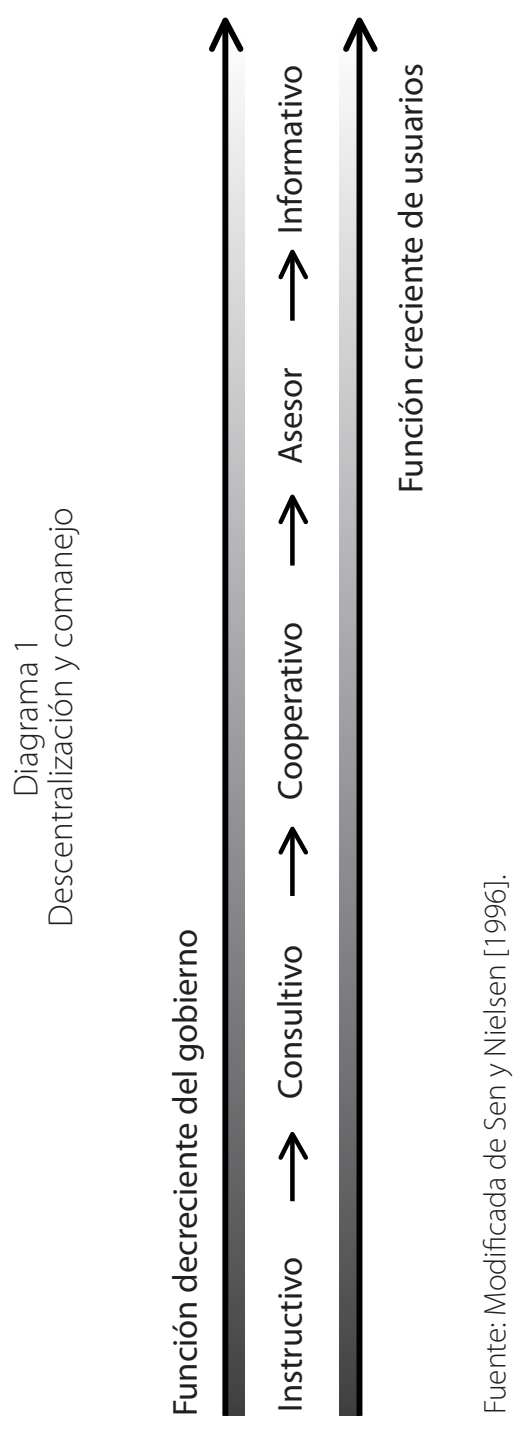


lo tanto, ambos conceptos son distintos, pero complementarios y no excluyentes.

Si se continúa hacia la derecha en el diagrama, la toma de decisiones pasa a los usuarios, pero con asesoramiento del gobierno; al final, la gestión es por completo descentralizada y la información gubernamental se utiliza como un elemento más para la toma de decisiones.

Según Ostrom [1990], hay varios principios de diseño para crear instituciones en las que se lleva a cabo la gestión cooperativa exitosa de los recursos de uso común. Estos principios han sido revisados por Burke [2001], quien apoyado en otros trabajos los complementa y resume de la siguiente manera:

- El recurso natural debe ser lo suficientemente pequeño y con límites definidos; ha de contar con indicadores claros de su calidad, de manera que los usuarios puedan comprender y acordar cuáles son los problemas y las soluciones.

- El número de usuarios debe ser lo suficientemente pequeño y concentrado cerca del recurso para que los costos de transacción (comunicación, monitoreo y vigilancia) no sean muy altos. De lo contrario, el riesgo de agotar o contaminar el recurso permanecerá latente.

- Los usuarios no deben tener diferencias marcadas en cuanto a necesidades, aspectos culturales o costos de acceso o preservación del recurso.

- Las instituciones u organizaciones pueden servir como base para lograr un régimen adecuado de manejo.

- El gobierno debe permitir a los usuarios locales la libertad de autoorganizarse. 
El extremo derecho del diagrama 1 significa un mayor grado de descentralización y por lo tanto una toma de decisiones exclusiva por parte de los usuarios. Sin embargo, una descentralización total no es garantía de éxito en la gestión de los recursos naturales, porque ésta conlleva el riesgo de fortalecer a grupos de interés que impongan decisiones en colusión con las autoridades locales. La concentración de poder en un solo usuario no sólo podría ser peor para otros usuarios, sino también para el recurso natural. No obstante, la planificación cuidadosa y la coordinación entre las instituciones podrían prevenir este problema. Una descentralización efectiva debe delegar decisiones de gestión al ámbito local, pero dentro de una política ambiental coherente y de largo plazo.

\section{El enfoQue DE LA TEORÍA DE JUEGOS ${ }^{4}$}

Los problemas de uso común de los recursos naturales que se describieron en la sección anterior involucran la interacción de toma de decisiones entre diversos usuarios. Es decir, las acciones de un agente económico (puede ser un productor, un consumidor o una autoridad ambiental) tienen repercusiones no sólo en la disponibilidad del recurso natural o en su propio beneficio, sino también para la colectividad que utiliza este mismo recurso.

4 Hay muchas formas de expresar situaciones sobre la gestión de los recursos naturales en forma de juegos que no pueden detallarse aquí. Para el lector interesado se recomienda ver Ostrom et al. [1994]. 
En la sección anterior se mencionó que una de las grandes aportaciones de Elinor Ostrom es la gestión cooperativa, en la cual los usuarios de recursos comunes interactúan para tomar decisiones en conjunto. Los principios teóricos de esta idea se basan en la teoría de juegos. De hecho, en el primer capítulo del Gobierno de los comunes [Ostrom, 1990], se hace una revisión sintética, pero muy clara, de la teoría de juegos sin recurrir a las matemáticas utilizadas tanto por economistas matemáticos como por sociólogos y antropólogos. En la presente obra se realizará una breve descripción de la teoría de juegos con algunas aplicaciones a la gestión de los recursos naturales.

La teoría económica neoclásica se basa en los principios del individualismo y la racionalidad, desde los cuales los agentes (consumidores, productores, gobiernos) toman decisiones para maximizar su utilidad o sus beneficios, o para minimizar los costos o daños. La teoría de juegos adopta estos mismos principios pero agrega otros dos muy importantes: la interdependencia y la información. Interdependencia se refiere a que las decisiones de los agentes no son tomadas de manera aislada, sino que los resultados de cada uno (como un nivel de utilidad o beneficio) dependen de las decisiones de otros. Entonces, para lograr un nivel de resultado en el objetivo deseado (maximizar o minimizar) deben aplicarse estrategias que dependen de las acciones de otros. Por ejemplo, un pescador sabe que los peces que obtiene ya no los pescará otro y lo mismo sucede a la inversa: si él no los captura, otros lo harán y él pescará menos.

Por otro lado, la información es clave para saber qué estrategia es la más adecuada para el logro del objetivo. 
Un ejemplo muy claro es la puesta en marcha de políticas ambientales, en la que se observa una interacción estratégica entre un tomador de decisiones (autoridad ambiental) y uno o varios usuarios de un recurso natural. A esta interacción se le llama modelo del agente-principal, en el que la autoridad ambiental representa al principal y un usuario o grupo de usuarios, al agente. El problema central es la información asimétrica: una o ambas partes poseen información que no van a revelar a la otra; en la práctica, el costo de una política ambiental puede ser muy alto si el principal no tiene suficiente información de los agentes y sus acciones.

La información asimétrica en este modelo se manifiesta en dos formas conocidas como selección adversa y riesgo moral. En la primera, el principal no conoce bien las características de los agentes y su estrategia para conservar un recurso natural puede ser muy ineficiente no sólo en términos monetarios sino en resultados de conservación.

Por ejemplo, supongamos que el gobierno ofrece un subsidio a los ejidos para la conservación de la biodiversidad. Si se aprueban todas las solicitudes para obtener el subsidio, tanto los ejidos en donde no hay riesgos para la biodiversidad como los ejidos en donde sí los hay recibirán el mismo monto. Esta política será ineficiente porque ejidatarios que no necesitaban el dinero lo reciben, lo que representa un costo de oportunidad para la sociedad. Aunque podría brindarse más apoyo a las áreas donde la presión sobre la biodiversidad sea más fuerte, en lugar de ello recibirían el mismo monto que los ejidos sin ese tipo de problemas. Para solucionar este problema es necesario que la autoridad, antes de poner en marcha un instrumento de gestión ambien- 
tal, pueda distinguir quién debe recibir el subsidio y quién no. Para eso requiere información previa sobre los agentes.

La otra manifestación de información asimétrica -el riesgo moral- se refiere al cumplimiento (o no), por parte del agente, de un trato hecho con la autoridad ambiental. Éste puede ser el caso del pago por servicios ambientales o por el retiro de tierras de cultivo, o el de los permisos para pescar. El principal aporta el dinero pero el agente puede no cumplir con las acciones comprometidas: a pesar de cobrar el subsidio para la conservación continúa la tala, la aplicación de químicos, la generación de residuos tóxicos o la pesca.

Para solucionar estos casos se necesita un monitoreo después de aplicar el instrumento de gestión, es decir, una inspección y vigilancia que verifique que el dinero otorgado se utiliza para los fines requeridos de conservación.

En resumen, hay tres aspectos fundamentales tratados por la economía de los recursos naturales: ¿cuándo extraer el recurso?, ¿cuánto hay que extraer?, y ¿quién lo debe extraer? Las respuestas de las dos primeras preguntas se refieren a la comparación entre el valor del recurso in situ o su valor en usos alternativos; la de la última tiene que ver con el régimen de propiedad de un recurso natural. 


\section{ECONOMÍA AMBIENTAL}

La economía ambiental es un campo aplicado de la economía neoclásica que se basa en el análisis microeconómico, sobre todo en las teorías del consumidor, de la empresa y de la interacción de los mercados, pero también adapta conceptos desarrollados por otras ramas de la economía, como las finanzas públicas y la organización industrial, para aplicarlos a los problemas ambientales [Kolstad, 2000: 4].

Algunos autores consideran que la mayor contribución de la economía ambiental se encuentra en los métodos para medir la demanda de un bien que no tiene mercado y asignarle un precio. Este tipo de valoración es exclusivo de la economía ambiental, pero puede tener un uso potencial en otras ramas de la economía.

La economía ambiental se ocupa del efecto de la economía en el ambiente, del significado de éste para la economía y de la forma de regular la actividad económica para que haya un equilibrio entre la calidad del ambiente, los intereses económicos y los de tipo social. En el centro de los problemas ambientales está la economía, el comportamiento de los productores y los deseos de los consumidores [Kolstad, 2000: 1].

Para algunos autores [Turner et al., 1993], el campo de estudio de la economía ambiental incluye dos conjuntos de problemas: los relacionados con el deterioro de los recursos naturales y los que se refieren a la contaminación, 
los cuales se analizan desde la siguiente secuencia lógica: a) evaluación de la importancia económica del deterioro ambiental, b) indagación de las causas económicas de ese deterioro y c) diseño de incentivos económicos para detener, reducir y revertir la degradación ambiental.

La economía es lo que distingue un producto químico "moralmente" neutro, como el dióxido de sulfuro, del contaminante dióxido de sulfuro; este último es el subproducto que se obtiene de producir una mercancía que la gente demanda, aunque al mismo tiempo, de manera inevitable, la gente reciba un daño del contaminante asociado al producto [Kolstad, 2000: 1].

En la mayoría de los casos la vinculación entre el disfrute de un producto y el daño de su efecto en el ambiente no se conoce o no se acepta. Un ejemplo típico sería la relación entre poseer un vehículo de alta cilindrada y elevado consumo de combustible, y la calidad del aire no sólo donde circula el vehículo, sino donde se procesa el combustible.

Si se parte de que la esencia del problema ambiental es la economía, las preguntas que tratará de resolver son: ¿cuáles son los incentivos que ocasionan la contaminación?, ¿cuál es el costo de abatirla?, ¿cuál es el balance adecuado entre costos y beneficios de contaminar?, ¿cuáles son los beneficios sociales del control de la contaminación? y ¿cuáles mecanismos de regulación pueden diseñarse para asegurar el balance correcto entre los costos y beneficios de contaminar? [Kolstad, 2000: 1].

A diferencia de la economía "a secas", que se basa sólo en aspectos positivos ajenos a juicios de valor, la economía ambiental incluye juicios normativos, aunque desde 
distintas perspectivas éstos sean objetables y se consideren ambivalentes.

Y también, a diferencia de la economía convencional que supone la economía como un sistema cerrado, la ambiental parte de que la economía es un sistema abierto ${ }^{5}$ cuyos procesos de producción, transformación y consumo involucran la generación de residuos y energía "inútil" que por último retornan al ambiente, aire, agua o suelo. Por principio económico de maximización de ganancias y de utilidad, los responsables de la producción y los consumidores no intentarán reducir estos residuos a menos que se les obligue a ello o que hacerlo les reditúe un beneficio.

La acumulación de residuos en un lugar y momento inadecuados puede provocar cambios biológicos o fisicoquímicos en el ambiente, que se conocen como contaminación. Si estos cambios causan daño a los animales, las plantas y su ecosistema, se dice que hay polución $n^{6}$ [Turner et al., 1993]. Si los efectos ambientales causan un daño a la salud humana o afectan de modo negativo su bienestar, los economistas reconocerán la existencia de polución económica; por lo tanto, la definición económica de polución conlleva dos tipos de efecto: los fisicoquímicos o biológicos que afectan en el ambiente y la afectación humana secundaria a éstos.

A los economistas ambientales no les interesa la polución fisicoquímica o biológica per se, porque no necesariamente

\footnotetext{
5 En los términos de Turner et al. [1993].

6 Puesto que el término inglés pollution no tiene equivalente en español, llamaremos polución, de manera arbitraria desde el punto de vista del lenguaje, al proceso específico al que se alude en inglés.
} 
significa que hay polución económica, esto es, que se de una pérdida de bienestar por la imposición de un costo externo. Este costo puede ir desde la reducción de experiencias placenteras ante paisajes deteriorados hasta la muerte por inhalación de gases tóxicos, pasando por la enfermedad y la disminución de las capacidades físicas humanas.

Pero incluso cuando hay polución económica, no siempre tiene que eliminarse; debe haber un reclamo de la sociedad, una demanda de compensación por el daño sufrido, para que el problema entre a la esfera de interés de la economía ambiental.

La economía ambiental surge con la aparición de varios textos relacionados con el tema hacia finales de los sesenta y principios de los setenta, periodo durante el cual tuvo lugar una acumulación de problemas ambientales que fueron el resultado de dos siglos de innovaciones tecnológicas y progreso desigual en la historia moderna.

Para algunos autores, los primeros atisbos de la economía ambiental aparecen con las contribuciones del grupo de trabajo Resources for the future a fines de los cincuenta; "despega" como disciplina a finales de los setenta y desde entonces a la fecha ha tenido un desarrollo continuo y ha ejercido una gran influencia en la toma de decisiones de política ambiental [Kolstad, 2000: 1].

Académicos como Turner et al. [1993] consideran que la economía ambiental tiene su origen en la primera mitad de los sesenta con la primera ola de pensamiento popular moderno "verde" y los primeros intentos de poner en marcha una política ambiental en los países desarrollados, fenómenos que se conocieron como ambientalismo. 
Otros especialistas consideran el libro de Rachel Carson, La primavera silenciosa ${ }^{7}$ (1962) -totalmente ajeno a la teoría económica-, el detonante de importantes temas ambientales, como: a) la conciencia ambiental de los sesenta y la aparición del movimiento ambientalista [Leff, 1998]; b) la inclusión del ambiente en la agenda de investigación de los economistas [Bohm, 1997]; c) la creación de un conjunto de instituciones y medidas de política ambiental en Estados Unidos ${ }^{8}$ y la prohibición de una larga lista de pesticidas, incluido el dieldrín [Kolbert, 2007].

Aspectos TEÓRICOS: DE LA TEORÍA DEL BIENESTAR A LA ECONOMía AMBIENTAL

Aguilera Klink y Alcántara [1994: 16] mencionan que muchos economistas están de acuerdo en que Pigou y Coase, aunque no directamente interesados en cuestiones ambientales, ${ }^{9}$ sientan las bases conceptuales de lo que hoy se conoce como economía ambiental: Pigou en el libro Welfare Economics, de 1920, y Coase en el largo artículo "El problema del coste social", de 1960.

7 El libro reporta la muerte de animales y la extinción de numerosas especies debido a la aplicación masiva de pesticidas (heptacloro y dieldrín) en la agricultura estadounidense desde finales de los cincuenta [Kolbert, 2007].

8 La Environmental Protection Agency y las leyes de aire limpio, de agua limpia y de especies en peligro.

9 De Pigou habría que rescatar su mención a la actitud depredadora que consume recursos agotables de la naturaleza y su propuesta de una acción del Estado en defensa de la conservación de los recursos naturales. 
En los cuarenta años que transcurren entre estas dos aportaciones, aparecen, entre otros, los artículos "Los fundamentos de la economía del bienestar", de Oscar Lange (1942), "Una dificultad en el concepto de bienestar social", de Kenneth Arrow (1950), "El equilibrio de la valuación y el óptimo de Pareto", de Gerard Debreu (1954), y "Dos conceptos de economías externas", de Tibor Scitovsky (1954):i1 todos ellos en referencia a los escritos de Pigou y Coase.

Divergencia entre productos netos marginales sociales y privados

Pigou parte de que aun en condiciones de competencia pura, puede haber divergencias entre el valor del producto neto marginal privado y el social. En el capítulo II de su libro La economía del bienestar [1946],1" define el producto neto marginal social como

el producto total [...] de los recursos invertidos [...] sin tener en cuenta a quiénes revertirán las partes de que se compone este producto. Todos los efectos, tanto positivos como negativos que recaen en terceras personas, se deben incluir al fijar el producto neto social.

El producto neto marginal privado es aquella parte del producto neto total [... debido al incremento marginal de los recursos [...], que revierte, en primera instancia [...], a la persona que ha invertido en dichos recursos. En ciertos casos es igual, mayor o menor que el producto neto marginal social, divergencias que

10 Todos recopilados en Arrow [1974] (primera edición en inglés de 1969).

11 Primera versión en español. 
se pueden presentar en el régimen de competencia, en el monopolio y en el monopolio bilateral [Pigou, 1946].

El origen de las divergencias entre los valores de los productos netos marginales social y privado que surgen en libre competencia ${ }^{12}$ reside en que, en algunas actividades, "una parte del producto [...] en vez de revertir en primer lugar a la persona que ha invertido en dicha unidad, revierte [...] como una partida positiva o negativa, a otras gentes" [Pigou, 1946].

El esquema de los efectos positivos o negativos (en personas que no producen la misma mercancía que el inversor) es: "una persona $A$, al efectuar algún servicio por el cual es retribuida una segunda persona $B$, al mismo tiempo rinde servicios o perjuicios a otras personas [...] de forma que el pago no puede ser exigido de las personas beneficiadas, ni indemnizadas las partes perjudicadas" [Pigou, 1946: 155]. Tiempo después a estos efectos se les llamó efectos externos en la esfera de la producción.

Como ejemplos positivos, a los que otros autores han recurrido una y otra vez, Pigou menciona: a) los beneficios de un faro adecuadamente ubicado que disfrutan los barcos que no pagan por su servicio, b) los recursos destinados a la reforestación cuyos efectos benéficos desbordan los lindes de las tierras del propietario que hizo la inversión y c) el servicio indirecto que proporciona una lámpara en el portal de una casa y que incrementa el alumbrado de una calle.

Entre los ejemplos de perjuicios indirectos señala: a) la fábrica construida en un lugar donde sólo hay villas y jardines,

12 Sólo nos referiremos a este tipo de divergencia, haciendo caso omiso de las surgidas del monopolio y del monopolio bilateral, que también examina en forma exhaustiva. 
y que destruye gran parte de las ventajas que se obtenían de la belleza del lugar y de la pureza del aire; $b$ ) la construcción de un edificio en un lugar excesivamente poblado que reduce los espacios al aire libre y el lugar de juego para los niños, y c) la producción y venta de bebidas alcohólicas que deberían tener un cargo por el exceso de costos en policía y cárceles que indirectamente representan. Los dos primeros son un indicio de lo que se formalizaría como una disminución de bienestar por pérdida de amenidades, una de las funciones de los bienes y servicios ambientales.

Pigou sostiene que, en estos casos, las divergencias entre los productos netos social y privado no pueden mitigarse modificando las relaciones contractuales entre las partes, proceso que Coase defendería más adelante, porque la divergencia procede de servicios o perjuicios causados a personas que no tienen ninguna relación contractual [Pigou, 1946: 163].

Sin embargo, señala que el Estado puede hacer que la divergencia desaparezca impulsando o restringiendo las inversiones en dichas actividades, y la forma más conocida de hacerlo es mediante el uso prudente de primas o impuestos..$^{13}$ Reconoce que abundan ejemplos positivos y negativos de la política intervencionista del Estado, pero señala que a veces es necesario recurrir a métodos coercitivos.

Ya Marshall, comenta Pigou, había propuesto que toda persona que edificara una casa en un distrito que hubiera llegado al máximo de población tolerable debería estar obligada a contribuir a la construcción de parques y lugares de esparcimiento.

13 Conocidos después como impuestos pigouvianos

46 
Externalidades: definiciones y debate

A los efectos positivos y negativos que afectan a terceros, Meade [1952] los denomina economías y deseconomías externas, respectivamente, y analiza los distintos tipos que pueden presentarse en conexión con ajustes marginales en situaciones de competencia pura. ${ }^{14}$

Meade propone dos tipos de economías y deseconomías externas. El primero, "factores de producción no pagados", se presenta cuando la acción de una industria A afecta las condiciones de producción de otra B, de manera distinta al incremento del precio del producto o de los factores en la industria B. Se trata de factores de la producción por los que un productor individual no pagó [Meade, 1952: 62]. El segundo tipo, "creación de atmósfera”, ocurre cuando las actividades de un grupo de productores generan una atmósfera favorable, o desfavorable, para las actividades de otra industria.

En los dos tipos de economías o deseconomías externas, las funciones de producción no necesariamente son homogéneas de primer grado. En el primer tipo hay rendimientos constantes a escala para la sociedad (no hay un problema adicional para ésta), pero no para los factores que cada industria emplea y paga. Para pagar a cada factor de acuerdo con el valor de su producto marginal social neto, se grava algunos factores y se subsidia otros; el beneficio de un impuesto adecuado financiará el gasto en un subsidio apropiado.

14 Supone funciones de producción homogéneas de primer grado y rendimientos constantes a escala. 
En el segundo tipo hay rendimientos constantes a escala en cada industria para los factores que controla y paga, pero no los hay para las dos industrias en conjunto porque la escala de operaciones de una industria es importante por el entorno que crea para la otra. En este caso, los subsidios (o impuestos) requeridos para promover (o desincentivar) la creación de un entorno favorable (o desfavorable) son adiciones (o sustracciones) netas a la carga fiscal de una sociedad. Al final, Meade reconoce que las economías o deseconomías externas pueden no corresponder a una de estas divisiones y contener características de ambas.

Para Scitovsky [1974], el concepto de economías externas no era claro; sus definiciones, escasas y poco satisfactorias, no explicaban de manera convincente la naturaleza y forma de los servicios gratuitos o las razones de su gratuidad.

La argumentación de Scitovsky retoma los supuestos de la teoría del equilibrio general ${ }^{15}$ (teoría estática) para sostener su principal conclusión: que la economía de mercado conduce a una situación de óptimo económico (en el sentido de Pareto), ${ }^{16}$ siempre y cuando los efectos económicos del comportamiento de una persona (o empresa) sobre el bienestar de otra se transmitan mediante los precios de mercado.

En la teoría del equilibrio (general o parcial), una economía de competencia perfecta es una situación de óptimo de Pareto, excepto cuando hay interdependencia entre los miembros de la economía, esto es, que sus relaciones no operen por medio del mecanismo de mercado. Scitovsky

\footnotetext{
15 Competencia perfecta y divisibilidad perfecta de los factores.

16 Y que Pigou cuestiona en La economía del bienestar.
} 
distingue cuatro tipos de interdependencia directa: a) "interdependencia de satisfacción entre los consumidores", b) "influencia directa del productor sobre la satisfacción de otra persona", c) influencia de la persona sobre las ganancias del productor y $d$ ) "economías y deseconomías externas" en el sentido de Pigou.

A diferencia de autores posteriores, para Scitovsky el cuarto caso, al que denomina economías externas tecnológicas porque se da entre funciones de producción, es excepcional, carece de importancia y es el único tipo de economía externa que puede surgir de la interdependencia directa entre productores en el marco de la teoría del equilibrio general [Scitovsky, 1974: 307].

Encuentra sólo dos ejemplos. Uno se refiere al caso en que varias empresas utilizan un recurso gratuito, pero de oferta limitada: pozos petroleros cuya extracción depende de la operación de otros pozos del mismo campo, o el pescador cuya pesca depende de las operaciones de otros pescadores. El otro caso se refiere a la empresa que utiliza un camino público y que debe asumir las pérdidas por saturación cuando otras empresas también lo usan.

Al lado de las economías externas tecnológicas, Scitovsky describe las economías externas pecuniarias que surgen tanto de la relación directa entre productores como de su vínculo en el mercado, y que coinciden con lo que Marshall denominó excedente de los consumidores y los productores, según fuera el caso.

Baumol y Oates [1982: 15] sostienen que hay diferentes clases de externalidades cuyas propiedades formales e implicaciones de política económica difieren en forma significativa; tal es el caso de las externalidades de bienes 
públicos y privados reconocidas por primera vez en forma explícita por Bator y Head. ${ }^{17}$

Estos autores resuelven las ambigüedades entre las externalidades tecnológicas y las pecuniarias al señalar que la diferencia no es que las pecuniarias afecten sólo los valores de las variables monetarias y no el de las reales, sino que no obligan a un desplazamiento en las funciones que relacionan cantidades de recursos como variables independientes y cantidades de producto o niveles de utilidad de los consumidores como variables dependientes. Baumol y Oates señalan dos condiciones para la presencia de una externalidad:

1. Que las relaciones de utilidad o producción de A incluyan variables reales (monetarias), cuyos valores son elegidos por otros (personas, empresas, gobiernos), sin atender los efectos en el bienestar de A. ${ }^{18}$

2. Que el agente cuya actividad afecta los niveles de utilidad de otro o entra en sus funciones de producción no recibe (o paga), en compensación por su actividad, una cantidad igual en valor que los beneficios (o costos marginales) ocasionados.

La segunda condición es necesaria si la externalidad ha de tener todas las consecuencias desagradables, incluyendo ineficiencias y mala asignación de recursos que se asocian con el concepto y que son reconocidas como fallas de mercado.

Baumol y Oates sistematizan el análisis de externalidades agotables (privadas) e inagotables (públicas) retoman-

17 Basado en Bator [1958: 351-379] y Head [1962: 197-219].

18 Diferencian esta condición de la interdependencia económica. 
do de Bator el estudio de los bienes públicos para los cuales el sistema normal de precios no funciona.

Una de las conclusiones más importantes de Baumol y Oates se refiere a las medidas de política pública; señalan que

dentro de cualquier versión plausible de una política de subsidios en la que resulte apropiado un sistema de impuestos pigouvianos, un sistema de subsidios llevará generalmente a una utilización ineficiente de recursos [...] y que la teoría ofrece poco apoyo para la utilización de subsidios como sustitutos de los impuestos en la regulación de las externalidades [Baumol y Oates, 1982: 229].

Con el tiempo, cambió el significado de economías y deseconomías externas, y en la actualidad se consideran, en esencia, un sinónimo de efectos externos en la esfera de la producción y, desde esta perspectiva, la contaminación generada por un productor que incrementa el costo inter alia de otros productores es quizá el caso más importante de una externalidad [Bohm, 1997].

Fallas de mercado y bienes públicos

En un sentido moderno las economías externas significan, como regla, que el precio de mercado en una economía competitiva de mercado no refleja los costos marginales sociales de producción y el sistema de mercado no puede alcanzar un estado de eficiencia por sí mismo.

De acuerdo con Hanley et al. [2007: 42], los mercados sirven para comunicar tanto las leyes de la naturaleza como las leyes humanas, pero en el caso de muchos bienes y servicios ambientales los mercados fallan si los precios no 
logran comunicar los deseos y restricciones de la sociedad de manera correcta, cuando no se asignan los recursos escasos para generar el mayor bienestar social.

Los precios de mercado pueden subestimar los servicios que la naturaleza proporciona o ser nulos para enviar la señal precisa sobre el valor total de un activo, como el de las especies que habitan un bosque.

Otras fallas de mercado, además de la contaminación mencionada por Bohm, son la destrucción del hábitat y las amenazas a la biodiversidad biológica resultado de la producción de bienes agrícolas y forestales, cuyos precios (madera, productos agrícolas y tierra) no generan un incentivo para reducir la destrucción del hábitat. La biodiversidad ${ }^{19}$ - soporte de la vida- y la protección del clima son bienes públicos puros porque los bienes y servicios que proveen son no-excluyentes y no-rivales. ${ }^{20}$

Un bien es no-excluyente si no es posible ni práctico impedir que algunos consumidores tengan acceso a él; si el bien está disponible para una persona, automáticamente lo está para todas las demás. Un bien es no-rival si el consumo que una persona hace de ese bien no disminuye su cantidad para otros consumidores [Kolstad, 2000: 81].

Los bienes ambientales pueden presentar combinaciones de estas características y, además, estas combinaciones pueden cambiar cuando se modifican algunas disposiciones legales o institucionales.

${ }^{19}$ La biodiversidad contribuye a la productividad, actúa como un seguro, es el hogar del conocimiento genético y proporciona servicios de filtración de agua y polinización al sistema [Hanley et al., 2007: 42].

20 La rivalidad, que también se conoce como sustracción, está vinculada con la divisibilidad de un bien. 
Cuadro 1

Bienes ambientales

\begin{tabular}{|c|c|c|c|c|c|}
\hline Bienes & Excluyentes & $\begin{array}{c}\text { No } \\
\text { excluyentes }\end{array}$ & $\begin{array}{c}\text { Exclusión } \\
\text { difícil }\end{array}$ & Rivales & $\begin{array}{l}\text { No } \\
\text { rivales }\end{array}$ \\
\hline Banco de peces & & * & & * & \\
\hline Agua del subsuelo & & * & & * & \\
\hline Agua superficial & & & * & * & \\
\hline Bosques & & & * & * & \\
\hline Playas privadas & * & & & & * \\
\hline Paisaje, aire & & * & & & * \\
\hline
\end{tabular}

Fuente: Adaptado de Turner et al. [1993].

En el caso de los bosques o el agua superficial en una cuenca, la exclusión ${ }^{21}$ es difícil y la rivalidad alta; este tipo de bien se conoce como bien o recurso de uso común (RUC).

Hanley sistematiza las fallas de mercado en cinco categorías: 1) externalidades, 2) no-exclusión, 3) no-rivalidad, 4) no-convexidad y 5) información asimétrica.

La propiedad común puede considerarse otro caso de falla de mercado en virtud de su característica de no-exclusión; cuando el acceso, legal o ilegal, a un recurso es libre para todos, hay incentivos para obtener los beneficios antes que otros, lo que conduce a su sobreexplotación. Hardin lo ejemplifica con el concepto tragedia de los comunes, y entiende por comunes el recurso en sí y no la propiedad comunal o colectiva del mismo. El acceso libre a un bien común

${ }^{21}$ La exclusión requiere un marco legal institucional que se traduzca en derechos de propiedad. 
también se ilustra en el juego no cooperativo de Nash, en el cual se sigue una estrategia de no-cooperación porque reporta mayores beneficios a los involucrados en el juego. El equilibrio de Nash se alcanza cuando ninguno de los participantes tiene incentivos para modificar su estrategia.

En sentido opuesto, Ostrom documenta algunos ejemplos de recursos de propiedad común donde los involucrados llegan a resultados cooperativos mediante la autogestión.

Lo que diferencia una externalidad de un bien público es que este último tiene como propósitos: la defensa nacional, la protección del clima o de la biodiversidad biológica, mientras que una externalidad es, por lo general, una consecuencia de una acción iniciada independientemente de su efecto.

La no-rivalidad de un bien público significa que el costo marginal de ofertar un bien a una persona adicional es cero. No se observa una eficiencia paretiana al establecer precios para excluir a alguien que obtiene beneficios marginales positivos de un bien público; por tanto, hay una falla de mercado porque ninguna empresa privada podría obtener beneficios de proveer un bien público puro a todo mundo como lo supondría la eficiencia de Pareto. Además, como todos se benefician de los servicios provistos por un bien público puro (ya que nadie puede ser excluido), hay una preocupación general de que la gente se comporte como "gorrona" o "polizonte" (free-rider) [Hanley et al., 2007: 61].

La convexidad se presenta cuando el daño está hecho; gráficamente se muestra en una curva de costo marginal ambiental decreciente porque la actividad económica ya desapareció como consecuencia de la externalidad, aun cuando la contaminación vaya en aumento. Esto podría ori- 
ginar que las curvas de costo marginal ambiental y de costo marginal de abatimiento se intercepten en más de un punto.

Otra falla de mercado ocurre cuando una persona, en una transacción, no tiene la información completa de las acciones de la otra persona o de las características de un bien. Sin información completa (que, por otra parte, resulta costosa), los mercados fallan al asignar recursos de manera eficiente. Los dos tipos de información asimétrica se refieren al riesgo moral (moral hazard) y la selección adversa.

El riesgo moral surge cuando la acción de una persona no puede ser observada por otra; si una agencia reguladora no puede vigilar las acciones de una empresa, ésta tendrá incentivos para no reducir la contaminación que genera.

Se dice que hay selección adversa cuando una persona no conoce las características de un producto o una empresa; por ejemplo, cuando no se opta por productos amigables con el ambiente -cuyo costo es mayor porque no están subsidiados por el ambiente- porque se carece de información sobre sus bondades. El comprador no tendrá incentivos para pagar el costo adicional de un ecoproducto si no cuenta con la información necesaria respecto de sus ventajas.

\section{AsPeCtOS APLICADOS}

Se han contemplado numerosas causas por las cuales el mercado falla cuando se trata de bienes y servicios que el ambiente proporciona, y que el resultado de la ausencia 
de precios que incentiven la reducción de una actividad contaminante es una demanda excesiva en relación con la capacidad de asimilación del ambiente.

\section{Internalizar y sustituir al mercado}

En economía ambiental se parte de que hay un nivel de contaminación óptimo que toma en cuenta la capacidad de asimilación del ambiente; en la gráfica 2, éste que se expresa en la intersección de las curvas de beneficio marginal neto (el beneficio que la empresa contaminante obtiene de producir una unidad más del bien) y costo marginal neto (el costo del daño ambiental resultado de la producción de esa unidad más). La cantidad de producción $Q^{*}$ causa un daño ambiental, pero éste es absorbido por el ambiente.

La teoría neoclásica ofrece dos formas de internalizar un daño ambiental por contaminación: mediante la intervención del gobierno por medio de la política ambiental o la solución de Coase -marginal por impracticable-, que propone el establecimiento de acuerdos entre los agentes involucrados. Para Coase [1960], lo importante es el costo de oportunidad subyacente en la determinación de beneficios y daños resultantes de acciones no independientes, y no se inclina por la compensación de un daño a menos que ésta represente un costo menor al daño ocasionado; si fuera mayor, la compensación no tendría lugar. Considera que la intervención externa (impuestos o subsidios determinados por el Estado) puede llevar a costos más elevados, aunque también reconoce el hecho de que los posibles acuerdos entre los involucrados conlleven un costo. Coase supuso que no habría costos de transacción, por lo que la 
Gráfica 2

Intersección de las curvas de beneficio marginal neto

y costo marginal neto

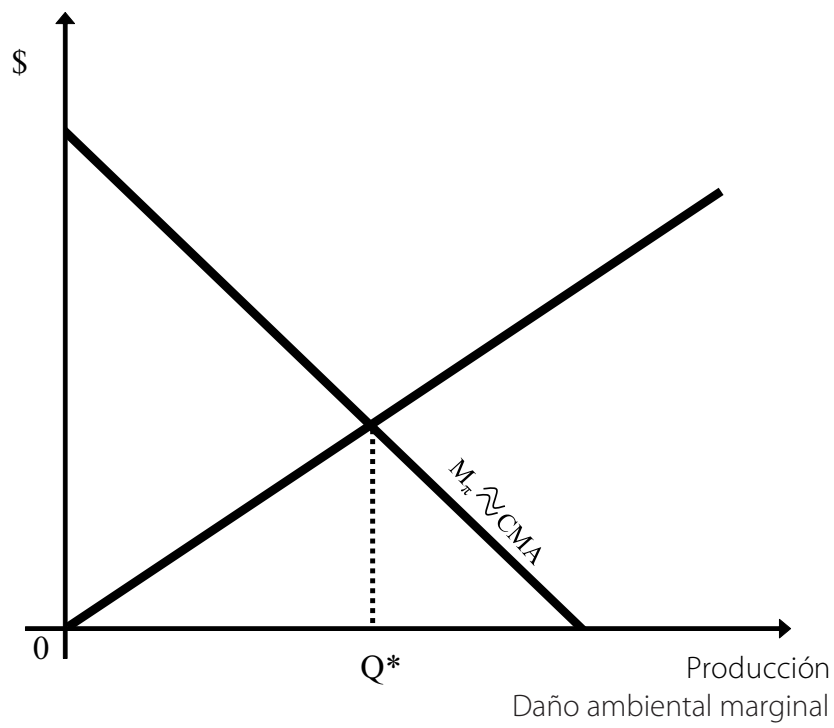

Fuente: Elaboración propia.

puesta en práctica de estas negociaciones se limita a problemas locales o en un ámbito menor.

La política ambiental, no siempre eficiente, intenta lograr que los mercados funcionen creándolos cuando no los hay o modificándolos mediante normas, regulaciones e incentivos para que los bienes y servicios ambientales entren a la estructura de costos. Esto lo hace con base en dos enfoques fundamentales: el indirecto o de mercado y el directo o regulatorio. 
El enfoque indirecto o de mercado

Durante las décadas de 1970 y 1980, la política ambiental de los países desarrollados se orientó fundamentalmente por el enfoque regulador; sin embargo, a principios de los noventa, cuando la recesión económica empezó a provocar graves problemas de empleo, la agenda ambiental se modificó para dar lugar a una reforma impositiva en la que los impuestos pigouvianos, ahora llamados verdes, empezaron a desplazar a los impuestos al trabajo, proceso que se conoce como doble dividendo.

1. Instrumentos económicos: impuestos y subsidios

En los países de la OCDE, el empleo de impuestos verdes se incrementó más de 50\% de 1987 a 1994 e incluso países de economías en transición como Polonia, Hungría y Estonia empezaron a considerar que los cargos e impuestos verdes, a pesar de su difícil aplicación, eran el mejor mecanismo para integrar la política económica con la ambiental [Ekins, 1999].

En el cuadro 2 se observan las ventajas que pueden encontrarse en los impuestos verdes en relación con las regulaciones.

Sin embargo, lo que en la teoría se considera prometedor, en la realidad enfrenta escollos que hacen del establecimiento de impuestos verdes una tarea ardua, sobre todo por la incertidumbre acerca de los costos del daño asociado a un determinado contaminante.

La determinación de los costos marginales ambientales, fundamentales para el establecimiento del impuesto, requiere la siguiente información científica y económica: 
Cuadro 2

Ventajas de los impuestos verdes

\begin{tabular}{lc}
\hline \multicolumn{1}{c}{ Impuestos } & \multicolumn{1}{c}{ Regulaciones } \\
\hline - Evasión difícil al administrarse mediante las & - Requieren inspecciones in situ \\
estructuras fiscales actuales & \\
- Incentivan la reducción de contaminantes, pues a & - No incentivan la reducción \\
medida que éstos disminuyen, el beneficio total & de otros contaminante \\
de la empresa se incrementa & \\
- Incentivan a las empresas a depositar fondos para & \\
la investigación y el desarrollo de tecnologías que & \\
reduzcan la contaminación & - Se evaden fácilmente \\
- Los impuestos sobre un contaminante pueden & \\
reducir las emisiones de contaminantes asociados & \\
\hline
\end{tabular}

Fuente: Elaboración propia.

- La producción real de bienes de la empresa.

- La "dosis" de contaminantes que esa producción genera.

- La acumulación de contaminantes a largo plazo.

- Los efectos de esos contaminantes en el ser humano.

- La respuesta humana a ese daño en términos monetarios.

- La evaluación monetaria del costo del daño.

A estas limitaciones hay que agregar la más importante: la reducción de beneficios por parte de la empresa. De allí la oposición sistemática de los sectores empresariales a que los gobiernos establezcan este tipo de impuesto, así como su preferencia por las regulaciones, que se evaden con mayor facilidad.

\section{Asignación de derechos de propiedad}

Organismos internacionales como el Banco Mundial consideran la indefinición de los derechos de propiedad como 
una de las causas fundamentales de la contaminación y el deterioro de los recursos naturales, y desde la década de 1980 han impulsado una estrategia de "definición" de derechos de propiedad.

En teoría, los derechos que se asignen pueden ser privados, comunales o públicos; en la práctica, en la mayoría de los casos la definición de los derechos de propiedad se ha traducido en la privatización de bienes públicos y comunales.

\section{Creación de mercados}

El intercambio de permisos de contaminación, certificados de emisiones o permisos de captura da lugar a la creación de mercados que requieren la definición de una meta de extracción o de una emisión máxima para el conjunto de agentes que participan en el mercado, a los cuales se asigna, de acuerdo con ella, el permiso de mercadeo correspondiente.

\section{Instrumentos fiscales}

Incluyen, además de los impuestos ya mencionados, los cargos y subsidios para lograr metas ambientales. Los más usados son los cargos sobre emisiones, los impuestos sobre insumos y productos, y la depreciación acelerada de activos.

\section{Instrumentos financieros}

Son de naturaleza similar a los instrumentos fiscales, pero se diferencian porque no necesariamente pertenecen al presupuesto público. Incluyen préstamos blandos, incentivos de localización, tasas de interés preferenciales, fondos ambientales para apoyar proyectos amigables con el ambiente y otros. 
6. Bonos o fianzas ambientales

El bono ambiental es un incentivo que se utiliza en paralelo con un sistema de responsabilidad por daño (liability) y tiene como objetivo que las empresas que extraen recursos naturales o que son potenciales contaminadoras adopten las medidas adecuadas para evitar o minimizar el daño ambiental. Si se produce el daño, los bonos deben asegurar la limpieza o restauración ambiental más efectiva.

\section{Sistemas de depósito-reembolso}

Establece un cargo, a manera de depósito, en el precio de un producto potencialmente contaminante (puede ser su envase, su empaque o el producto mismo) cuando su vida útil ha acabado y se desecha. Este depósito se reembolsa cuando el material residual del producto es acopiado por un centro acreditado para su reciclaje o disposición ambientalmente adecuada, con lo que se evita la contaminación potencial. Los depósitos reembolsables trasladan la responsabilidad del daño ambiental a los productores y consumidores.

8. Instrumentos de información social y transparencia de mercados

Están relacionados con actitudes autorreguladoras de la conducta de empresas y consumidores para reducir el efecto negativo de su actividad en el ambiente. Proponen generar incentivos para despertar el interés de la comunidad por la protección y conservación ambiental, alentando su función en la vigilancia y el control social. En este conjunto de instrumentos se ubican diversos mecanismos de "cumplimiento voluntario" de metas ambientales, así como los 
procesos de establecimiento, auditoría y certificación de sistemas de gestión ambiental en las empresas y del ciclo de vida del producto, bajo el régimen de normas Iso14000.

El enfoque directo

Normas y estándares. El sistema regulatorio directo o de comando y control, como suele llamársele, propone dos opciones que el contaminador seleccionará en función del costo de abatimiento y el pago del derecho. Los contaminadores para los que el costo de control es muy alto preferirán pagar el derecho y aquéllos con un bajo costo optarán por instalar equipo de tratamiento. De esta forma el costo total de cumplimiento tenderá a disminuir.

A pesar de que las regulaciones directas se consideran ineficientes, los sistemas de control de contaminación en funcionamiento en los países industrializados y en varios países en desarrollo, entre ellos México, se basan en estos instrumentos. Las diversas fuentes de ineficiencia que se reconocen al enfoque de comando y control se observan en el cuadro 3.

Las regulaciones directas, que fueron la forma de poner en práctica el principio "el que contamina paga" (PpP), ${ }_{12}^{22}$ otorgan al contaminador un derecho de facto a descargar un nivel de efluente aceptable libre de cargos; una vez alcanzado dicho nivel, ya no hay incentivos para reducir la contaminación.

22 Por las siglas en inglés de polluter pays principle. 
Cuadro 3

Enfoque directo

Normas

- Requiere recursos de la agencia reguladora en información que los contaminadores poseen. Se supone que los contaminadores conocen mucho mejor que el gobierno el costo de abatimiento de una emisión contaminante

- El cumplimiento es sobre un determinado estándar generalmente sujeto a un tipo de tecnología, por ejemplo, "la mejor tecnología de control disponible", 0 a otras tecnologías de "fin de tubería"

- Los costos de control para no rebasar los mínimos permitidos serán diferentes para cada contaminador

- Una vez establecida una regulación no hay incentivo alguno para reducir la contaminación por debajo de los límites que establece

- Las opciones técnicas son limitadas y puede haber sesgos en las soluciones tecnológicas hacia la investigación y el desarrollo de alternativas de fin de tubería, lo que puede crear cierto conflicto entre el desarrollo tecnológico, el ambiente y la competitividad

Fuente: Turner et al. [1993].

La valoración del medio ambiente: problemas y mediciones

La economía ambiental plantea que el valor económico total de un bien ambiental está integrado por su valor de uso (vu) y su valor de no-uso (vNu). Los valores de uso pueden dividirse en valores de uso directo (VuD), valores de uso indirecto (vul) y valores de opción (vo). La categoría de valores de no-uso comprende los valores de existencia (VEx) [Toledo, 1997].

No importa qué tan esotérico o intangible sea un bien ambiental, su protección, por lo general, requiere dinero [Kolstad, 2000: 290] y resulta conveniente preguntar a la gente cuánto está dispuesta a contribuir para proteger un bien ambiental, tenga éste un valor de uso o de no-uso. 
Disponibilidad a pagar y estimación de la demanda de un bien ambiental

Si la teoría del consumidor integra bienes que tienen un valor en el ambiente es porque todos los problemas ambientales involucran un balance entre el uso del dinero en bienes y servicios convencionales o en la protección ambiental. Desde el punto de vista del consumidor, este balance se expresa en la curva de demanda que muestra cuánto se está dispuesto a pagar por un bien ambiental.

La curva convencional de demanda establece la cantidad demandada como una función del precio, pero si no hay mercado, como sucede con los bienes y servicios ambientales, tampoco hay precio. Sin embargo, conceptos similares pueden usarse en lugar de los convencionales.

Cada uno de los puntos de una curva de demanda individual de un bien convencional indica, para una cierta cantidad de ese bien, en cuánto valora el consumidor una unidad más, esto es, su disponibilidad marginal a pagar. En este sentido, el concepto análogo al precio es la disponibilidad marginal a pagar y el equivalente al excedente del consumidor es la disponibilidad total a pagar.

Hay tres enfoques básicos para estimar la demanda por bienes ambientales y de estimar de manera indirecta su valor:

1. Las preferencias reveladas: requieren la observación de una selección real en un mercado para de allí inferir el balance entre el dinero y el ambiente. Hay tres métodos en este enfoque: a) los precios hedónicos: detectan cómo el precio de un bien convencional (una casa, por ejemplo) varía cuando un bien ambiental relacionado con éste (la calidad del aire en la vecindad 
de la casa) cambia, y de allí se infiere el valor del bien ambiental; b) la producción doméstica: se supone que el consumidor combinará bienes privados con el bien ambiental para "producir" otro bien, el cual es la verdadera fuente de utilidad. Si se observa el gasto en el bien privado complementario, se obtiene el límite más bajo del valor del bien (o mal) ambiental $y, c)$ el método del costo de viaje: se utiliza para estimar las curvas de demanda y el valor monetario de los espacios naturales (parques nacionales, áreas naturales protegidas y otros), ${ }^{23}$ bajo el supuesto de que hay una transacción implícita entre los costos de viaje y el valor o precio que debería pagar el visitante por acceder a un lugar específico.

2. Las preferencias declaradas: se basan en encuestas a muestras de consumidores potenciales de un bien ambiental en las que se pregunta qué tanto valoran un bien ambiental. El método dominante en esta categoría es la valuación contingente, cuyo nombre significa, literalmente, "¿si hubiera un mercado, cuánto pagaría por el bien ambiental?" Este enfoque es controversial porque la selección real está ausente.

3. Los mercados híbridos, que pueden ser mercados experimentales o construidos: la valuación contingente es un tipo de mercado construido donde el investigador diseñará una situación en la que no hay el mercado y lo genera. Un mercado construido puede ser hipo-

${ }^{23}$ Estudios que se inscriben en una corriente catalogada como economía de la recreación. 
Esquema 2

Métodos que estiman la demanda de un bien ambiental

Fuente: Elaboración propia.

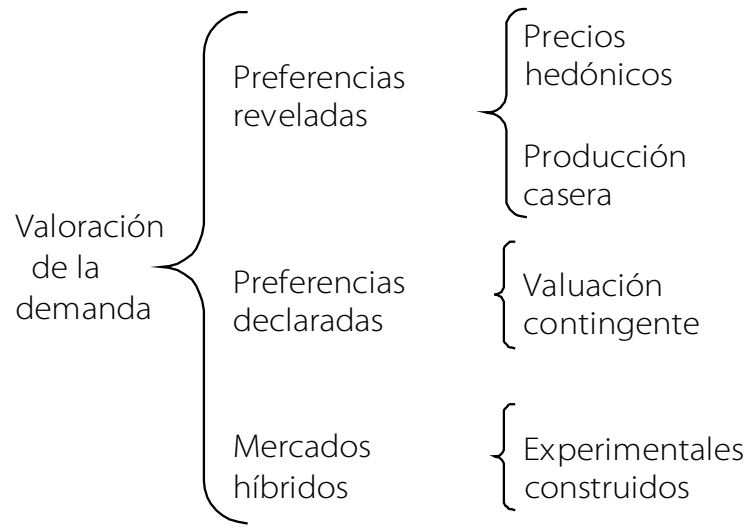

tético o real, ${ }^{24}$ resultado de un experimento de laboratorio para generar información acerca de cómo la gente intercambia dinero para bienes ambientales. Los experimentos de laboratorio son interesantes porque permiten que el investigador acceda a cuestiones para las que la información de mercado no está disponible y porque involucran decisiones reales sobre los recursos (se introduce dinero "real" en línea), lo cual es una ventaja sobre la valuación contingente. La desventaja de estos experimentos es que son costosos, con frecuencia involucran muestras seleccionadas no aleatoriamente y resultan difíciles de generalizar. Otro tipo de mercado construido es el referéndum oficial.

${ }^{24}$ Kolstad cita un estudio de Bishop et al. [1983] en el que construyen un mercado para comprar y vender permisos de caza de patos, a partir de lo cual generaron una curva de demanda de permisos de caza. 
Métodos que no requieren estimar la demanda

Hay otros métodos que no requieren estimar la demanda; éstos son el método de dosis-respuesta, los costos de reemplazo, los costos evitados y los de oportunidad.

1. Dosis-respuesta: requiere datos que relacionen una respuesta fisiológica (ya sea en plantas, animales o humanos) con el estrés producido por la contaminación. Ejemplo: estudios de salud ambiental.

2. Costo de reemplazo: calcula los costos de sustituir los servicios ambientales por alternativas tecnológicas y puede ser una medida de los costos de restauración. Ejemplos: los costos de depuración de aguas, los programas de reforestación y de monitoreo de la calidad del aire, de derrames petroleros, etcétera.

3. Costos evitados: llamados de comportamiento de mitigación o gastos preventivos, se refieren a los gastos de las personas en bienes o servicios que eviten daños al ambiente o la salud. Ejemplo: tomar agua embotellada si se percibe que el agua de la red pública está contaminada; el costo en que se incurre es una medida del valor de la calidad del agua.

4. Costo de oportunidad: toda decisión significa costos y beneficios asociados; elegir una opción es rechazar muchas otras y los beneficios que no adquirimos por hacer una elección representan el costo de oportunidad de esa elección. Aunque no es una técnica de valuación, ha demostrado ser una herramienta muy útil en la toma de decisiones [Turner et al., 1993]. 


\section{ECONOMÍA ECOLÓGICA}

El origen de la economía ecológica radica en el interés por aportar un enfoque diferente y complementario al de la economía ambiental y la de los recursos naturales. Los problemas ambientales con efectos socioeconómicos se agravan día con día y los estudiosos de la economía ecológica postulan que el problema está en cómo percibimos la relación entre el medio ambiente y la sociedad. La idea fundamental es que con los principios de la economía neoclásica no se pueden resolver los problemas ambientales, por lo que proponen una relación estrecha, basada en las leyes de la termodinámica, entre los procesos ecosistémicos y socioeconómicos. Por ello, el origen de la economía ecológica proviene de descubrimientos y corrientes de pensamiento tanto de la economía como de la ecología.

En este sentido, el origen de la economía ecológica y probablemente también de la economía de los recursos naturales se remonta a las ideas de los fisiócratas, una escuela de pensamiento económico del siglo xvIII fundada por François Quesnay (1694-1774) y Anne Robert Jacques Turgot (1727-1781). Esta corriente de pensamiento afirmaba la existencia de una ley natural que aseguraba el buen funcionamiento del sistema económico sin la intervención del gobierno, es decir, que las leyes humanas debían estar en armonía con las leyes de la naturaleza. En particular, enfatizaban la importancia de la agricultura como la principal 
actividad económica [Costanza et al., 1997a y 1997b]. Con base en esta corriente de pensamiento y analizando más a fondo la actividad agrícola en el siglo xIX, Thomas Malthus (1766-1834) menciona que el crecimiento poblacional seguirá una tendencia exponencial siempre y cuando haya suficientes recursos naturales, esto es, que hay un límite para la producción agrícola y por tanto para el crecimiento [Costanza et al., 1997a y 1997b]. David Ricardo (1772-1823), por su parte, describe cómo la superficie agrícola aumenta en relación con el crecimiento poblacional y cómo el incremento de los precios agrícolas conlleva a la intensificación y a un mayor uso de fertilizantes.

Poco más tarde, dos de las contribuciones más importantes a la economía ecológica son las de Sadi Carnot (18221888) y Rudolph Clausius (1796-1832), quienes plantearon los principios básicos de las leyes de la termodinámica. Sadi Carnot expuso los primeros planteamientos de la termodinámica en su estudio de 1824: Reflexiones sobre la potencia motriz del fuego y sobre las máquinas adecuadas para desarrollar esta potencia. Después, Rudolph Clausius difundió las aportaciones de Carnot e introdujo el concepto de entropía.

Uno de los personajes más importantes en la historia de las ciencias naturales y la ecología es Charles Darwin (1809-1882), quien en 1859 publica El origen de las especies por medio de la selección natural o la preservación de las razas preferidas en la lucha por la vida, donde postula que todas las especies de seres vivos han evolucionado de un pasado común mediante un proceso llamado selección natural y explica la biodiversidad como un proceso evolutivo de selección natural. Las contribuciones sobre la evolución de Darwin fueron muy importantes y se retomaron para en- 
tender los sistemas en desequilibrio y dinámicos [Costanza et al., 1997a y 1997b]. Un defensor de la teoría darwinista fue Ernest Haeckel (1834-1919), naturalista que estudió la evolución y fue el primer científico en usar, en 1866, la palabra œecologia, ${ }^{25}$ definiéndola como "la economía de la naturaleza".

Otro personaje importante en las ciencias sociales y económicas fue John Stuart Mill (1806-1873), que sostenía, como lo hacían los fisiócratas, que el capital natural no podía ser sustituido por el capital humano o tecnológico.

Las aportaciones de Karl Marx (1818-1883) en su obra El capital: crítica a la economía política han sido retomadas por muchos estudiosos en la materia que destacan las contribuciones de este autor a los principios del desarrollo sustentable y la forma como la distribución de los recursos y la renta de la tierra afecta el desarrollo.

Otra aportación importante a la economía de los recursos naturales es el principio de Hotelling (1931) sobre la asignación intertemporal de los recursos no renovables; Hotelling sostiene que el recurso natural no renovable puede ser aprovechado en forma sustentable si la tasa de crecimiento del precio del recurso es igual que la tasa de descuento [Pearce y Turner, 1990].

Alfred James Lotka (1880-1949) fue el primer científico del campo de la biología en vincular la economía con la ecología de una manera cuantitativa. Este autor proponía que la selección natural estaba dada por los organismos que utilizan de manera más eficiente la energía y extendió este pensamiento al uso de la energía no renovable. Asimismo, los

25 Ecología, del latín oikos (casa) y logos (conocimiento). 
modelos bioeconómicos que propuso son el primer ejemplo de integración de variables ecológicas y económicas.

Uno de los modelos bioeconómicos más sencillos aplicado en pesquerías es el de Gordon-Schaefer (1954), en el que la captura pesquera se considera en función de la biomasa y el esfuerzo pesquero. Los modelos bioeconómicos pesqueros y forestales incorporan variables de las poblaciones biológicas y hoy en día se cuenta con modelos aún más complejos que integran variables del ecosistema.

De manera paralela, Nicholas Georgescu-Roegen (19061994) fue el primer investigador que en su obra La ley de la entropía y el proceso económico vincula las leyes de la termodinámica y la economía, indicando que los recursos naturales son la energía disponible en un sistema cerrado, por lo que su uso sólo puede decrecer debido a que ésta se degrada y dispersa. En sus trabajos sobre economía del desarrollo, en particular del análisis insumo-producto y las funciones de producción, enfatiza que todos los procesos económicos requieren energía y todos generan desechos.

Desde la perspectiva de la ecología, Howard T. Odum (1924-2002) inicia el estudio de los ciclos de los materiales y los flujos de energía en un ecosistema (flujos ecosistémicos). El conocimiento generado por Odum fue muy importante porque describió las principales características de los ecosistemas y propuso indicadores para definir los flujos que tienen lugar en los mismos. Estos indicadores fueron retomados después por autores como Robert Costanza (1950) y Crowford Stanley Holling (1930) para describir la salud de los ecosistemas, la estabilidad ecológica y la resiliencia. En 1968, Herman Daly (1938) retoma los principios expuestos por los fisiócratas y por Georgescu-Roegen y 
propone la idea del "estado estable de la economía" (steady state), e indica, de nuevo, que el crecimiento económico tiene límites biofísicos. A partir de los setenta se constata la inquietud de varios científicos por reintegrar la economía con la ecología y la economía ecológica comienza a distinguirse como una nueva disciplina que se separa de la economía de los recursos naturales y la economía ambiental.

La economía ecológica se consolida en la década de 1980, cuando se organiza el congreso Integrating Ecology and Economics, en Suecia, en 1982, y con la aparición, en 1987, de la revista Ecological Modelling, de la que se publica un número especial sobre la integración entre economía y ecología. Un año después se funda la International Society for Ecological Economics (ISEE) y se publica el primer número de la revista Ecological Economics. Varios investigadores que pertenecen a la ISEE han hecho aportaciones importantes a la economía ecológica, cuyo principal objetivo y el de sus miembros es reintegrar la economía y la ecología.

BREVE DEFINICIÓN DE LA ECONOMÍA ECOLÓGICA

La economía ecológica es la ciencia que estudia la integración de variables ambientales, sociales, económicas, políticas y éticas, buscando la coevolución de estas disciplinas con la finalidad de proponer soluciones a los problemas de sustentabilidad. Los fundamentos básicos de la economía ecológica son las leyes de la termodinámica, aunque también se incluyen procesos ecosistémicos y otras variables de índole social y política. 
La economía ecológica busca la integración de la dinámica de los ecosistemas en los distintos instrumentos de la política ambiental y la coevolución entre la economía, la ecología y las ciencias políticas [Martínez y Jusmet, 2000], para lo cual es necesario generar nuevos conceptos y metodologías [Curtis, 2004]. La economía ecológica argumenta que la economía ha pasado de una era en la que el capital humano era el factor limitante del desarrollo, a otra en la cual el capital natural es el factor limitante.

\section{ConCEPTOS EN LOS QUE SE BASA LA ECONOMÍA ECOLÓGICA}

Las leyes de la termodinámica son la base teórico-conceptual de la economía ecológica y explican por qué la economía se considera un subsistema de los flujos energéticos globales. Ejemplo de ello es el cambio climático, proceso que significó la transformación de los insumos naturales y los ecosistemas para el crecimiento económico, el cual no sólo genera desechos, sino cambios en los flujos energéticos que producen variaciones climáticas. Los conceptos descritos a continuación son importantes para entender la lógica de la economía ecológica, la escasez de los recursos y los límites del crecimiento económico.

\section{Las leyes de la termodinámica}

La termodinámica es una rama de la física que estudia la circulación de la energía y cómo la energía infunde movi- 
miento, y analiza los efectos de los cambios de la temperatura, la presión y el volumen de los sistemas.

Define varios tipos de sistemas: abiertos, cerrados y aislados. Los sistemas abiertos tienen flujos de energía y materia con el exterior; los cerrados sólo tienen intercambio de energía con el exterior, pero no de materia, y el sistema aislado no tiene intercambios con el exterior o con el medio.

Los animales, por ejemplo, somos sistemas abiertos porque usamos oxígeno, agua, nutrientes y energía, y excretamos agua, calor, dióxido de carbono y otros nutrientes [Common y Stagl, 2005].

Las leyes de la termodinámica estudian la transformación de la energía; puesto que para este tema hay bibliografía especializada, aquí sólo se describirán de manera muy sintética. La primera ley dice que la energía no se crea ni se destruye, se conserva y sólo se transforma. Lo anterior significa que cualquier proceso de transformación de los recursos naturales utiliza energía que es transformada y genera desechos; es decir, la energía proveniente de los recursos naturales se convierte en otra y ese proceso utiliza energía.

La segunda ley de la termodinámica se conoce como ley de la entropía, palabra que proviene del griego y significa transformarse. En termodinámica, la entropía es una medida de la energía que no puede utilizarse para producir trabajo. Si un sistema es altamente desordenado (que tiene una distribución aleatoria), tiene alta entropía y tenderá a reorganizarse. La entropía llega a su máximo cuando el sistema es homogéneo porque ya no hay desorden. Un sistema abierto no tiene equilibrio termodinámico y varía en relación con el intercambio de materia y energía en el ambiente. La tercera 
ley de termodinámica no se menciona puesto que carece de relevancia en el tema que nos ocupa.

Georgescu-Roegen propuso una cuarta ley de la termodinámica en 1971. Consiste en que no sólo la energía en un sistema aislado sería irreversible, sino también la materia en un sistema cerrado, lo que equivale a decir que el reciclado total es imposible. La economía convierte un sistema de baja entropía en otro de alta entropía. Sin embargo, este planteamiento ha sido refutado por varios autores, en particular por Bianciardi et al. [1993], quienes afirman que el reciclado total es posible en un sistema cerrado pero a expensas de una gran cantidad de energía, con el consiguiente aumento de la entropía. Por lo tanto, lo que Georgescu-Roegen postuló puede ser explicado por la segunda ley de la termodinámica, sin que sea necesaria una cuarta.

Odum [1971] y Costanza [1980] sugirieron que la energía es el único factor de producción verdaderamente escaso porque "no es reproducible" y propusieron una valoración de los recursos no económica, sino energética. Estos autores utilizan el concepto de energía para sostener que tanto la productividad biológica como la actividad económica existen gracias a la energía solar. La teoría energética del valor plantea que éste se relaciona de manera directa con los flujos de energía (y materia) provenientes del sol. Sin embargo, esta teoría ha sido muy cuestionada por Faber et al. [1996], quienes señalan que la entropía es el marco conceptual de una limitante física, un concepto que permite comprender la escasez o utilidad de los recursos, pero que no constituye una teoría alternativa del valor. 
Uno de los principios básicos de la economía ecológica es que la economía es un subsistema de los ciclos energéticos, entre los que se incluyen los ciclos ecosistémicos. El crecimiento económico y en particular la creación y transformación de productos dependen de los insumos de energía y materia provenientes de la naturaleza. Durante este proceso se genera también energía y materia que pueden o no ser reutilizadas para el mismo proceso de transformación o para otros procesos diferentes. Por ello el crecimiento económico depende de la permanencia de los ecosistemas debido a que utiliza insumos y flujos energéticos que se derivan de éstos. La economía es un subsistema y la capacidad del capital natural para proveerlo ha disminuido $33 \%$, mientras que la demanda se ha incrementado $50 \%$ en los últimos treinta años [Daly y Farley, 2004].

Conceptos básicos de los ecosistemas

Definición de ecosistema y flujos energéticos

Un ecosistema es la interacción de los seres vivos con el ambiente; es una comunidad más su ambiente físico en un lapso determinado. Puesto que significa la relación de los seres vivos entre sí y con su ambiente, es necesario conocer los flujos de energía entre ellos. Por ejemplo, para analizar un ecosistema de una laguna costera se tiene que estudiar los organismos vivos que la habitan y su relación con variables ambientales como temperatura, salinidad, turbidez, oxígeno disuelto, entre otras. 
Los servicios ecosistémicos son las funciones del ecosistema que sustentan y proveen al ser humano. Se reconocen cuatro categorías generales de servicios ambientales que pueden ser válidas para diferentes tipos de ecosistemas [Millenium Ecosystem Assessment, 2005]:

1. Servicios de aprovisionamiento: son productos que se obtienen de la naturaleza, principalmente alimentos, fibras, combustibles, recursos genéticos, productos bioquímicos, medicina natural y productos farmacéuticos, recursos ornamentales y agua.

2. Servicios de regulación: son los beneficios que se obtienen de la regulación de procesos ecosistémicos; entre éstos se considera el mantenimiento de la calidad del aire, la regulación climática, la regulación del ciclo hidrológico, el control de la erosión, la purificación de agua y el manejo de desperdicios, la regulación de enfermedades humanas, el control biológico, la polinización y la protección contra fenómenos hidrometeorológicos.

3. Servicios culturales: son los beneficios no materiales que la gente obtiene de los ecosistemas a partir de la reflexión, el desarrollo de conocimiento, la recreación y las experiencias estéticas. Comprenden la diversidad cultural, los valores espirituales y religiosos, los sistemas de conocimiento, los valores educacionales, la inspiración, los valores culturales e históricos, así como la recreación y el ecoturismo, entre otros.

4. Servicios de soporte: son los servicios necesarios para la producción y el mantenimiento del resto de los servicios; se diferencian de los demás porque su influencia se percibe en periodos más largos que el 
resto (por ejemplo, la formación del suelo o la provisión de oxígeno).

Los ecólogos denominan ecosistemas maduros a los que funcionan con una baja entropía; son sistemas ordenados en los que los flujos de energía se han optimizado.

\section{Biodiversidad}

La biodiversidad es la variedad y variabilidad de la vida en la Tierra en todos sus niveles, genes, especies y ecosistemas, así como los procesos ecológicos y evolutivos que la sostienen.

La biodiversidad es la suma del número de especies (incluido el ser humano) y la abundancia de organismos de cada una de estas especies. Un ecosistema de gran biodiversidad es un ecosistema complejo con muchos flujos de energía.

La teoría ecológica postula que entre más biodiversidad tenga un ecosistema, su capacidad para responder a disturbios será mayor. Esta capacidad se denomina resiliencia.

\section{Salud de los ecosistemas}

La salud de los ecosistemas puede medirse mediante indicadores o a partir del análisis de los flujos energéticos. Odum fue el primer autor en proponer algunos parámetros para medir la salud de los ecosistemas; su alumno Costanza [1997a y 1997b] considera que un ecosistema es saludable si tiene resiliencia, sucesiones normales y un balance en los componentes del sistema, como vigor y organización. Vigor es el flujo de energía en el sistema; organización es la complejidad de la 
cadena alimenticia y una medida de ésta es la biodiversidad; la combinación de ambos es la ascendencia. Estos valores le confieren mayor o menor resiliencia al sistema.

La resiliencia es la capacidad de un sistema para recuperarse de disturbios o para absorber el estrés y está determinada por la efectividad del sistema [Costanza et al., 1997a y 1997b]. También se define como la rapidez con la que una variable o un ecosistema regresan a su estado de equilibrio después de una perturbación [Pimm, 1984]. Asimismo se conoce como la capacidad de un sistema para mantener su estructura y patrones de funcionamiento después de alguna afectación [Holling, 1986].

Las perturbaciones naturales forman parte de la evolución de los ecosistemas y son importantes para su integridad y resiliencia. Un sistema con mayor resiliencia será un sistema con mayor estabilidad debido a una mayor capacidad de resistir las perturbaciones. La resiliencia y la estabilidad se relacionan con la productividad de los sistemas, que depende no sólo de su biodiversidad, sino de los flujos de energía. La resiliencia es un concepto que también se aplica a sistemas económicos y sociales [Peterson, 2000].

\section{Capacidad de carga}

La capacidad de carga en ecología es la máxima población que puede soportar indefinidamente un determinado hábitat sin dañar de manera permanente la productividad del ecosistema del que depende una determinada población.

Para la sustentabilidad, la capacidad de carga se define como el máximo ritmo de consumo de recursos y producción de residuos y emisiones que puede sostenerse a largo 
plazo en los ámbitos regional y mundial sin dañar la integridad y la productividad ecológica [Arrow et al., 1995].

El concepto de capacidad de carga se ha utilizado mucho en temas de sustentabilidad y en particular se ha extendido a la ecología humana, en la que se ha observado que la aplicación de este concepto es muy compleja [Seidl y Tisdell, 1999].

\section{Principios de LA ECONOMía ECOLÓGICA}

Los conceptos básicos antes descritos permiten comprender los principios de la economía ecológica; éstos son:

- La Tierra es un sistema termodinámicamente cerrado en el cual la economía es un subsistema de un sistema global, lo que significa que hay límites para el crecimiento económico.

- La Tierra es un sistema complejo donde está presente una gran incertidumbre y ciertos procesos son irreversibles, por lo que debe considerarse el principio precautorio.

- Las instituciones y el manejo de los recursos naturales deben ser proactivos, simples, adaptativos y capaces de poner en marcha políticas basadas en un entendimiento de los sistemas complejos [Costanza et al., 1997a y 1997b].

- Los puntos mencionados dan pie para cuestionar algunos aspectos de la economía neoclásica, como escala, distribución inicial, complementariedad versus 
sustitución, crecimiento y desarrollo, utilidad y preferencias, entre otros.

Por su importancia, se menciona la visión de la economía ecológica sobre los puntos antes citados.

\section{Principales debates de LA eCONOMÍA ECOLÓGICA}

Escala, distribución justa y asignación eficiente

La economía neoclásica analiza la asignación eficiente de recursos y la distribución equitativa pero no considera la escala, la cual se refiere a que los sistemas funcionan en un ámbito global y por lo tanto para medir la capacidad de los ecosistemas de regenerar insumos y absorber desechos es importante considerar las causas y efectos en los ámbitos local, regional y global. Este principio no tiene nada que ver con las economías de escala en economía, sino con los flujos energéticos de los ecosistemas y la capacidad de los mismos para reabsorber la energía y la materia, es decir, con su capacidad de carga y resiliencia. La escala es un concepto muy importante y se relaciona con la distribución justa y la asignación eficiente.

Distribución justa se refiere a la división equitativa de los recursos entre la gente y las generaciones, y los instrumentos para conseguirla pueden ser el mercado o la política fiscal. Asimismo, para lograr la distribución equitativa entre generaciones es necesario considerar que los ecosistemas funcionan a una escala global. Por ejemplo, el cambio climático se debe a patrones de producción y consumo que 
nos han llevado a generar efectos ambientales tan intensos que han provocado cambios en los ciclos biogeoquímicos y el clima en general. La sustentabilidad fuerte postula que las generaciones futuras tienen el derecho a poseer el mismo capital natural que nosotros, lo cual es una distribución justa; sin embargo, no podrán disfrutar de las especies que se extingan a causa del cambio climático. Por ello, en este ejemplo, la distribución justa del capital natural depende de a qué escala observemos los problemas ambientales y la escala global nos da un panorama mucho más completo e integral. Si la capacidad de los ecosistemas no se sobrepasa, las generaciones futuras podrán aprovechar los recursos naturales, por lo que habrá una distribución justa.

Asignación eficiente se refiere a la división de los recursos entre las diferentes alternativas de bienes, es decir, cuánto de un recurso es utilizado para producir coches, zapatos u otro bien. Una buena asignación es eficiente y corresponde a las preferencias de los consumidores en función de su poder de compra. El instrumento que regula esta asignación es el sistema de precios de mercado, que resulta de la interacción de la oferta y la demanda. El problema es que ese sistema de precios sólo incluye el costo de oportunidad de asignar recursos entre los bienes, pero no el costo del capital natural que se pierde en su producción. La economía ecológica propone que para tener una asignación eficiente se deberían integrar los costos de oportunidad del deterioro de los ecosistemas y, en consecuencia, el efecto en la escala. El sistema de precios tampoco incluye los costos sociales o externalidades, conceptos que se han explicado en la sección sobre economía ambiental. 
Es importante, por tanto, determinar primero la escala y la distribución justa, y después la asignación eficiente.

Complementariedad versus sustitución

Una de las causas más importantes de la escasez y depredación de los recursos naturales es que la economía neoclásica considera que los recursos pueden ser sustituidos entre sí. Por ejemplo, un bosque de encino puede ser sustituido por un bosque de eucaliptos si produce los mismos beneficios económicos netos; no obstante, con esta perspectiva no se consideran los efectos que tenga en el ecosistema y los costos que este cambio de especies tendría en la economía. Este enfoque significa que el capital natural no es una limitante para el desarrollo económico, lo cual, desde la perspectiva de la economía ecológica, es un error. En este sentido, Daly [Costanza et al., 1997a y 1997b] menciona que la extracción no debe exceder la calidad de regeneración y la producción de desechos no debe sobrepasar la capacidad de asimilación.

\section{Crecimiento y desarrollo}

La economía ecológica plantea que el crecimiento económico se ha dado a expensas del deterioro del capital natural y que el incremento en el producto interno bruto (PIB) no refleja los costos de oportunidad de la pérdida de los ecosistemas y sus servicios. Por lo tanto, el crecimiento económico no necesariamente conduce a un desarrollo económico y mucho menos a un desarrollo sustentable. El desarrollo económico y el mayor bienestar social deben considerar que la pérdida 
del capital natural resulta más costosa a largo plazo y que es necesario tomar en cuenta los límites de los ecosistemas. Los ecosistemas deben prevalecer en el tiempo, aunque sufran cambios y evolucionen como parte de su desarrollo; sin embargo, si la intervención del hombre es brutal y no permite que los sistemas se recuperen, entonces no habrá desarrollo sustentable. Un lago, por ejemplo, tiene la capacidad de asimilar cierta cantidad de nutrientes, pero una vez sobrepasado el límite, el sistema se satura y los organismos mueren por falta de oxígeno. Aunque varios autores han discutido el tema de la sustentabilidad y el desarrollo, el artículo de Daly [2005],"Economía en un mundo lleno", representa una síntesis de los principales debates acerca del tema.

\section{Bienestar social}

La economía ecológica cuestiona cómo se mide el bienestar y en particular hace una crítica fuerte al concepto de producto interno bruto como medida para determinar el bienestar social, porque en su contabilidad no integra el costo de la degradación ambiental como indicador del bienestar. Por ejemplo, si un país obtiene $1 \%$ de su PIB mediante la explotación de un recurso natural, pero sólo 0.3\% es aprovechado de manera sustentable, el restante $0.7 \%$ genera una grave presión ambiental; si ésta no se considera, se estará sobreestimando el crecimiento económico. En las últimas décadas se ha realizado un esfuerzo por integrar los procesos de pérdida de capital ambiental a la contabilidad nacional para determinar el producto interno neto ecológico (PINE); sin embargo, la información integrada en estas cuentas aún es insuficiente. 
Ya se expusieron los principales conceptos de debate de la economía ecológica en relación con la economía neoclásica y se señaló que los principales objetivos de política ambiental para la economía ecológica son escala sustentable, distribución justa y asignación eficiente [Costanza et al., 1997a y 1997b].

La economía ecológica busca tener propuestas concretas en la política ambiental, por medio de la aplicación de diversos instrumentos económicos y de planeación. Tanto la economía ambiental como la ecológica utilizan diversos instrumentos, como los regulatorios, de comando y control - los incentivos económicos (impuestos, subsidios, permisos, certificaciones, depósito y reembolso, entre otros) para lograr objetivos ambientales [Costanza et al., 1997a y 1997b]. La diferencia radica en que la economía ecológica argumenta que ninguna política será eficiente si no hay concordancia entre políticas sectoriales sobre un mismo objetivo: la sustentabilidad. En este sentido no sólo es indispensable que las políticas públicas sean transversales e incluyan objetivos ambientales, sino que debe haber coordinación entre ellas.

La economía ecológica plantea la necesidad de que las políticas se basen en el conocimiento científico de los ecosistemas, específicamente en su dinámica, y que además se tomen en cuenta los aspectos de equidad, ética y justicia. Incorporar la dinámica de los ecosistemas en la toma de decisiones es una tarea muy compleja desde el punto de vista de la metodología, así como por falta de información. Para de- 
terminar la tasa de aprovechamiento de un recurso resulta importante incorporar diversas variables ecosistémicas y no sólo poblacionales; asimismo, es necesario saber analizar sistemas complejos y manejar recursos con incertidumbre, es decir, aplicando el principio precautorio. El tema de la escala en este sentido es de suma importancia porque los recursos naturales deben analizarse a largo plazo y a mayor escala.

En la búsqueda de integrar la complejidad de los ecosistemas y al mismo tiempo solucionar problemas ambientales en el corto plazo, Costanza et al. [1997a y 1997b] describen las principales políticas que si bien se sustentan en la economía neoclásica, han tenido consenso entre los economistas ecológicos: cobrar un impuesto mayor a quienes generan un deterioro del capital natural; incentivar el uso de nuevas tecnologías y procesos que afecten menos el ambiente; aplicar el principio "el que contamina paga", pero asegurando que el costo del deterioro ambiental sea el adecuado, e incentivar a los países a imponer un sistema de tarifas ecológicas en las que se privilegie a los países con prácticas sustentables.

DifERENCIAS ENTRE ECONOMÍAS ECOLÓGICA Y AMBIENTAL

Las economías ambiental y la ecológica tienen como objetivo comprender las relaciones entre el ser humano, la economía y el medio ambiente con la finalidad de redirigir la economía hacia la sustentabilidad [Venkatachalam, 2007].

Sin embargo, divergen en varios aspectos conceptuales y metodológicos en la medida en que la economía ambien- 
Cuadro 4

Diferencias entre economías ambiental y ecológica

\begin{tabular}{|c|c|c|}
\hline & Economía ambiental & Economía ecológica \\
\hline Bases teóricas & $\begin{array}{l}\text { La economía neoclásica se basa en } \\
\text { racionalidad, eficiencia y modelos } \\
\text { de equilibrio } \\
\text { El medio ambiente es parte de la } \\
\text { economía } \\
\text { Alta sustitución de recursos }\end{array}$ & $\begin{array}{l}\text { El límite del crecimiento depende de } \\
\text { la naturaleza, mayor escala espacial } \\
\text { y temporal, sustentabilidad a largo } \\
\text { plazo, complejidad de los sistemas } \\
\text { La economía es parte de un } \\
\text { subsistema y depende del medio } \\
\text { ambiente } \\
\text { Baja sustitución de recursos }\end{array}$ \\
\hline $\begin{array}{l}\text { Visión sobre el } \\
\text { capital natural }\end{array}$ & $\begin{array}{l}\text { Los recursos se analizan en } \\
\text { términos económicos si son } \\
\text { relativamente escasos } \\
\text { Los recursos pueden sustituirse } \\
\text { entre sí o por la tecnología } \\
\text { Los límites biofísicos no son } \\
\text { considerados }\end{array}$ & $\begin{array}{l}\text { Todos los recursos son importantes } \\
\text { sean escasos o no } \\
\text { Los recursos tienen poco margen de } \\
\text { sustitución } \\
\text { Los límites biofísicos y la } \\
\text { complejidad del ecosistema son } \\
\text { considerados }\end{array}$ \\
\hline $\begin{array}{l}\text { Valuación } \\
\text { económica }\end{array}$ & $\begin{array}{l}\text { Basada en las preferencias reveladas } \\
\text { y expresadas }\end{array}$ & $\begin{array}{l}\text { Basada en las preferencias reveladas, } \\
\text { los valores intrínsecos y las variables } \\
\text { de comportamiento }\end{array}$ \\
\hline $\begin{array}{l}\text { Crecimiento } \\
\text { poblacional }\end{array}$ & $\begin{array}{l}\text { Los factores económicos e } \\
\text { institucionales tienen un papel } \\
\text { fundamental en la relación entre } \\
\text { crecimiento poblacional y deterioro } \\
\text { ambiental }\end{array}$ & $\begin{array}{l}\text { La población es el principal } \\
\text { consumidor del capital natural }\end{array}$ \\
\hline Bienestar & $\begin{array}{l}\text { Evitar el deterioro ambiental } \\
\text { para tener mayor equidad } \\
\text { intergeneracional y con ello } \\
\text { mayores oportunidades económicas } \\
\text { y de bienestar }\end{array}$ & $\begin{array}{l}\text { La distribución inequitativa es causa } \\
\text { del deterioro ambiental y la equidad } \\
\text { y la eficiencia se analizan de manera } \\
\text { independiente }\end{array}$ \\
\hline
\end{tabular}

Fuente: Elaboración propia. 
tal se basa en la economía neoclásica y la economía ecológica modifica algunos de sus conceptos y métodos. Las diferencias fundamentales se presentan en el cuadro 4.

La economía ecológica busca integrar la complejidad de los ecosistemas y reconoce que el capital natural es un factor limitante del crecimiento económico; su análisis es más complejo y, por lo mismo, en muchas ocasiones resulta difícil que a partir de él puedan hacerse propuestas concretas de política.

En cambio, la economía ambiental ha logrado aplicar un mayor número de instrumentos económicos porque no considera la complejidad de los sistemas y no reconoce que la economía es un subsistema.

Por tanto, hoy en día se está en una encrucijada entre construir metodologías nuevas con un enfoque integral de los problemas ambientales y uno pragmático para la solución de estos problemas en el corto plazo. 


\section{BIBLIOGRAFÍA}

Aguilera Klink, Federico y Vicente Alcántara [1994], De la economía ambiental a la economía ecológica, Barcelona, Economía Crítica.

Arrow, Kenneth J. [1974], "Una dificultad en el concepto de bienestar social", en Kenneth Arrow y Tibor Scitovsky (comps.), Ensayos sobre economía del bienestar, MéxiCO, FCE, pp. 151-171.

- Bert Bolin, Robert Costanza, Partha Dasgupta, Carl Folke, Crowford Stanley Holling, Bengt-Owe Jansson, Simon Levin, Karl-Göran Mäler, Charles Perrings y David Pimentel [1995], "Economic growth, carrying capacity, and the environment", Science, 268: 520-521.

- y Tibor Scitovsky [1974], Ensayos sobre economía del bienestar, México, FCE.

Azqueta Oyarzún, Diego [1994], Valoración económica de la calidad ambiental, Madrid, McGraw-Hill.

Bator, Francis M. [1958], "The anatomy of market failure", Quarterly Journal of Economics, LXXII: 351-379.

Baumol, William y W. Oates [1982], La teoría de la política económica del medio ambiente, Barcelona, Antoni Bosch.

Bianciardi, C., E. Tiezzi y S. Ulgiati [1993], "Complete recycling of matter in the frameworks of physics, biology and ecological economics", Ecological Economics, 8(1):1-5. 
Bishop, Richard, Tomas A. Heberlein y Mary Jo Kealy [1983], "Hipothetical bias in contingent valuation: results form a simulated market", Natural Resources Journal, 23(3): 619-633.

Bohm, Peter [1997], The Economics of Environmental Protection. Theory and Demand Revelation, Reino Unido, Edward Elgar.

Burke, Bryan [2001], "Hardin revisited: a critical look at perception and the logic of the commons", Human Ecology, 29: 449-476.

Coase, Ronald [1960], "The problem of social cost", Journal of Law and Economics, 3: 1-44, octubre.

Common, Mick y Sigrid Stagl [2005], Ecological Economics: An Introduction, Cambridge, Cambridge University Press.

Costanza, Robert [1980], “Embodied energy and economic valuation", Science 210:1219-1224.

— [2000], "Social goals and the valuation of ecosystem services", Ecosystems, 3: 4-10.

-, John Cumberlan, Herman Daly, Robert Goodland y Richard Nogaard [1997a], "An introduction to ecological conomics: Chapter 2. Encyclopedia of Earth", Science, 268: 620-521.

- John Cumberlan, Herman Daly, Robert Goodland y Richard Nogaard [1997b], "An introduction to ecological economics: Chapter 4. Encyclopedia of Earth", Science, 268: 1-34.

Curtis, lan A. [2004], "Valuing ecosystem goods and services: a new approach using a surrogate market and the combination of a multiple criteria analysis and a 
Delphi panel to assign weights to the attributes", Ecological Economics, 50 (3-4):163-194

Daly, Herman E. [2005], "Economics in a full world", Scientific American: 100-107, septiembre.

—_ y Joshua Farley [2004], Ecological Economics: Principles and Applications, Washington DC, Island Press.

Ekins, Paul [1999] "European environmental taxes and charges: recent experience, issues and trends", Journal of Ecological Economics, 31: 39-62

Faber, M., R. Manstetten y J.L.R. Proops [1996], Ecological Economics - Concepts and Methods, Cheltenham, Edward Elgar

Field, C. Barry [1996], Economía ambiental. Una introducción, Bogotá, McGraw-Hill Interamericana.

Hanley, Nick, Shogren F. Jason y White Ben [2007], Environmental Economics in Theory and Practice, Nueva York, Macmillan.

Hardin, Garreth [1968], "The tragedy of the commons", Science, 162: 1243-1248.

Head, J. G. [1962], "Public goods and public policy", Public Finance XVII, 3: 197-219.

Holling, C.S. [1986], "The resilience of terrestrial ecosystems: local surprise and global change", W.C. Clark y R.E. Munn (eds.), Sustainable Development of the Biosphere. Cambridge, Cambridge University Press: 292-317.

Kolbert, Elizabeth [2007], "Human nature", 28 de mayo, The New Yorker: 23-24.

Kolstad, Charles D. [2000], Environmental Economics, Nueva York, Oxford University Press. 
Lange, Oscar [1974], "Los fundamentos de la economía del bienestar", en Kenneth Arrow y Tibor Scitovsky (comps.), Ensayos sobre economía del bienestar, México, FCE. Leff, Enrique [1998], Saber ambiental, México, Siglo XXI. List, John A. y Art de Zeeuw [2002], Recent Advances in Environmental Economics, Reino Unido, Edwar Elgar.

Martínez Alier, Joan y Jordi Roca Jusmet [2000], Economía ecológica y política ambiental, México, PNUMA, FCE.

Meade, E. James [1952], "External economies and diseconomies in a competitive situation", marzo, The Economic Journal, 62(245): 54-67.

Millenium Ecosystem Assessment [2005], Ecosystems and Human Well-Being: Biodiversity Synthesis, Washington DC, World Resource Institute.

Neumayer, Eric [1999], Weak Versus Strong Sustainability: Exploring the Limits of Two Opposing Paradigms, Edward Elgar, Cheltenham.

Odum, Howard T. [1971], Environment, Power, and Society, Nueva York, John Wiley \& Sons Inc.

Ostrom, Elinor [1990], Governing the Commons: The Evolution of Institutions for Collective Action, Cambridge, Cambridge University.

_-, Roy Gardner y James Walker [1994], Rules, Games and Common-Pool Resources, Ann Arbor, The University of Michigan Press.

Pearce, David W. [1998], Economics and Environment, Northampton, Mass, Edward Elgar.

- y R. K. Turner [1990], Economics of Natural Resources and the Enviroment, Baltimore, Johns Hopkins University.

Perrotini, Ignacio y Ricker Martin [1999], "Algunas reflexiones sobre la economía ambiental. Introducción al 
número especial", Investigación Económica, 54(227): 15-25.

Peterson, G. [2000], "Political ecology and ecological resilience: An integration of human and ecological dynamics", Ecological Economics, 35: 323-336.

Pigou, Arthur Cecil [1946], La economía del bienestar, Madrid, Aguilar.

Pimm, S. L. [1984], "The complexity and stability of ecosystems", Nature 307: 322-326.

Scitovsky, Tibor [1974], "Dos conceptos de economías externas", en Kenneth Joseph Arrow y Tibor Scitovsky (comps.), Ensayos sobre economía del bienestar, MéxiCO, FCE, Pp. 13-27.

Seidl, Irmi y Clem A. Tisdell [1999], "Carrying capacity reconsidered: from Malthus' population theory to cultural carrying capacity", Ecological Economics, 31(3): 395408, diciembre.

Sen, Sevaly y Jesper Nielsen [1996], "Fisheries co-management: a comparative analysis", Marine Policy, 20: 405418.

Tietenberg, Thomas H. [1994], Economics and Environmental policy, Londres, Aldershot Hants.

Toledo Ocampo, Alejandro [1997],"La valuación económica de la biodiversidad en México", en Economía Ambiental, Lecciones de América Latina, Instituto Nacional de Ecología: 229-240

Turner, R. Kerry [2001], "The place of economic values in environmental valuation", en lan J. Bateman y Ken G. Willis (eds.), Valuing Environmental Preferences: Theory and Practice of the Contingent Valuation Method in the 
US, EU and Developing Countries, Nueva York, Oxford University Press.

_- David Pearce e lan Bateman [1993], Environmental Economics: An Elementary Introduction, Nueva York, Harvester Wheatsheaf.

Venkatachalam, Lakshmi [2007], "Environmental economics and ecological economics: Where they can converge?", Ecological Economics, 61: 550-558.

96 
NOTAS 





Introducción a las economías de la naturaleza es una obra del Instituto de Investigaciones Económicas de la Universidad Nacional Autónoma de México. Se terminó de imprimir el 15 de noviembre de 2010. Se tiraron 300 ejemplares en impresión digital en los talleres de Publidisa, Calzada Chabacano núm. 69, planta alta, col. Asturias, México, DF. La formación tipográfica estuvo a cargo de Carlos José Bravo Nieto; se utilizó la fuente Myriad Pro de 8, 9, 10 y 11 puntos sobre papel cultural de $90 \mathrm{~g}$ y los forros en cartulina sulfatada de $240 \mathrm{~g}$. El cuidado de la edición estuvo a cargo de Hélida De Sales Y. 
